SALVADOR SÁNCHEZ VINCES

\title{
AVALIAÇÃO DA ATIVAÇÃO DE CÉLULAS \\ POLIMORFONUCLEARES CIRCULANTES EM RATOS COM PERIODONTITE INDUZIDA POR LIGADURA
}

Dissertação apresentada ao Programa de Pós-Graduação em Farmacologia do Instituto de Ciências Biomédicas da Universidade de São Paulo, para obtenção do Título de Mestre em Ciências. 


\section{SALVADOR SÁNCHEZ VINCES}

\section{AVALIAÇÃO DA ATIVAÇÃO DE CÉLULAS \\ POLIMORFONUCLEARES CIRCULANTES EM RATOS COM PERIODONTITE INDUZIDA POR LIGADURA}

Dissertação apresentada ao Programa de Pós-Graduação em Farmacologia do Instituto de Ciências Biomédicas da Universidade de São Paulo, para obtenção do Título de Mestre em Ciências.

Área de concentração: Farmacologia

Orientador: Prof. Dr. Marcelo Nicolas Muscará

Versão corrigida. A versão original eletrônica, encontra-se disponível tanto na Biblioteca do ICB quanto na Biblioteca Digital de Teses y Dissertações da USP (BDTD).

São Paulo

2017 



\section{CATALOGAÇÃO NA PUBLICAÇÃO (CIP) Serviço de Biblioteca e informação Biomédica do Instituto de Ciências Biomédicas da Universidade de São Paulo}

Ficha Catalográfica elaborada pelo(a) autor(a)

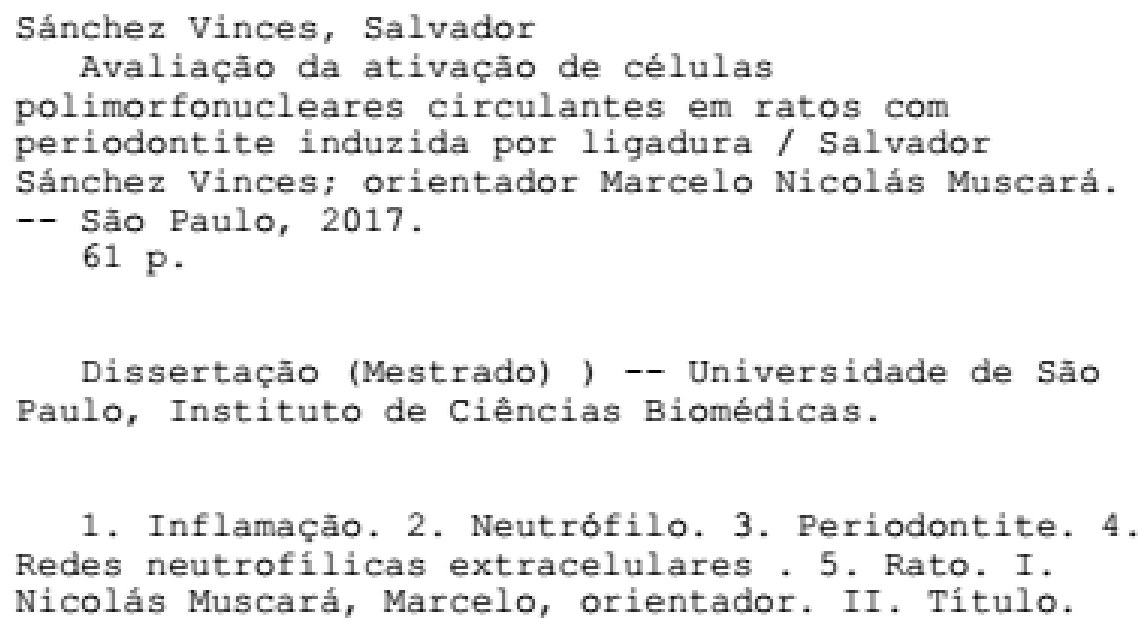

1. Inflamação. 2. Neutrófilo. 3. Periodontite. 4. Redes neutrofilicas extracelulares. 5. Rato. I. Nicolás Muscará, Marcelo, orientador. II. Título. 
Candidato(a):

Salvador Sánchez Vinces

Título da Dissertação:

Avaliação da ativação de células polimorfonucleares circulantes em ratos com periodontite induzida por ligadura.

Orientador(a): $\quad$ Marcelo Nicolás Muscará

A Comissão Julgadora dos trabalhos de Defesa da Dissertação de Mestrado, em sessão pública realizada a ................................., considerou
( ) Aprovado(a)
( ) Reprovado(a)

Examinador(a): Assinatura:

Nome:

Instituição:

Examinador(a): Assinatura:

Nome:

Instituição:

Presidente: Assinatura:

Nome:

Instituição: 


\begin{tabular}{|c|c|}
\hline UNIVERSIDADE DE SÃO PAULO \\
INSTITUTO DE CIÊNCIAS BIOMÉDICAS \\
Cidade Universitária “Armando de Salles Oliveira" \\
Av. Prof. Lineu Prestes, 2415 - Cep. 05508-900 São Paulo, SP \\
Telefone :(55) (011) 3091.7733 -e-mail: cep@icb.usp.br \\
COMISSÃO DE ÉTICA NO USO DE ANIMAIS
\end{tabular}

Decl. CEUA.062/2014.

D E C L A R A Ç Ã O

Em adendo ao Certificado 170/11/CEUA, aprovado em 14.02.12 e por solicitação do Prof. Dr. Marcelo Nicolás Muscará, responsável pela linha de Pesquisa, autorizo a inclusão do aluno Salvador Sánchez Vinces ao Projeto de Pesquisa "Avaliação do papel do óxido nítrico e espécies relacionadas na doença periodontal em ratos" uma vez que se trata de utilização da mesma espécie animal e de métodos experimentais similares ao Projeto.

São Paulo, 25 de agosto de 2014.

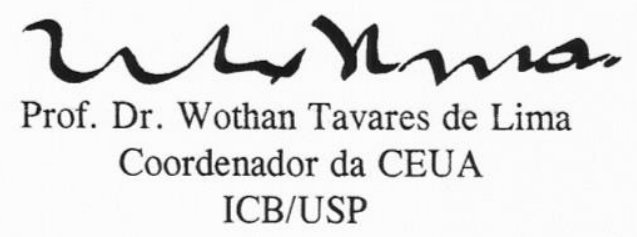


Dedico este trabalho:

Aos meus pais, Elmer e Angelita.

Aos meus irmãos Braulio, Ulvia, Elmer e Angelita À Jennifer. 


\section{AGRADECIMENTOS}

\section{A Deus.}

Ao professor Dr. Marcelo Nicolás Muscará. Muito obrigado por me permitir começar neste caminho da ciência, pela oportunidade, orientação, confiança e paciência que fizeram possível este trabalho.

À professora Dra. Soraia Costa e aos meus amigos e colegas do laboratório. Agradeço seu apoio, sugestões e ajuda. Especialmente grato à Flávia Neto por sua ajuda e conhecimentos nesta área.

À Dra. Simone Texeira por sua constante guia paciência e disposição.

Ao pessoal do Laboratório de Biologia Celular do Dr. José Belizário pela disposição e ajuda. Muito especialmente à Jennifer Montoya por estar sempre disposta a me ajudar, pelo incentivo e por sempre estar ao meu lado nas etapas mais importantes da minha vida.

A CAPES, a Universidade de São Paulo e ao Brasil por fazer possível este trabalho.

À minha família por seu incentivo e apoio incondicional.

Aos meus animais de experimentação.

Muito obrigado. 


\section{RESUMO}

Sánchez-Vinces S. Avaliação da ativação de células polimorfonucleares circulantes em ratos com periodontite induzida por ligadura. [dissertação (Mestrado em Farmacologia)] - Instituto de Ciências Biomédicas, Universidade de São Paulo, São Paulo; 2017.

Embora seja reconhecido que as doenças periodontais e outras infecções orais são causadas por bactérias, na realidade é o próprio sistema imunológico inato dos pacientes o grande responsável. Os neutrófilos, células chave do sistema imune inato, são responsáveis por detectar e eliminar os invasores microbianos e induzir parte da resposta do sistema imune. Estas células, que são carregadas com enzimas e outros compostos com forte atividade citotóxica, também são responsáveis pelos danos causados durante a fase inflamatória prolongada que ocorre quando eles se tornam hiperativos ou cronicamente ativos por estímulo bacteriano ou por imunoreguladores. Dados recentes sugerem um potencial "loop" da ativação inflamatória oral-sistêmica que é identificado pela presença de produtos da atividade neutrofílica em locais onde o processo inflamatório não foi inicialmente desenvolvido. Avaliando marcadores de atividade neutrofílica, como a produção de ânion superóxido, liberação da enzima mieloperoxidase (MPO) e a formação de redes neutrofílicas extracelulares ("neutrophil extracellular traps" - NETs), evidenciamos a presença desses e as diferenças entre ratos controle e ratos com periodontite. A periodontite foi induzida pela colocação subgingival de uma ligadura de algodão ao redor dos primeiros molares inferiores, e após 7 dias, neutrófilos foram isolados do sangue periférico. Nossos resultados mostram um aumento da quantidade de neutrófilos circulantes, assim como a resposta destas células provenientes dos animais com periodontite ante diferentes estímulos in vitro em comparação aos animais Sham. A produção de ânion superóxido por neutrófilos circulantes de ratos com periodontite foi maior quando estimulados com forbol-12-meristate-13-acetato (PMA; $100 \mathrm{nM}$ ) ou Zimosan (100 partículas/cel); no caso da liberação de MPO, PMA, Zimosan ou N-formilmetionil-leucil-fenilalanina (fMLP $2 \mu \mathrm{M}$ ) produziram efeitos maiores nos neutrófilos de ratos com periodontite. A formação de NETs foi também maior nos neutrófilos dos ratos com periodontite em resposta ao PMA. Além das respostas estimuladas, a liberação de MPO e a formação de NETs em condições basais foram maiores nos neutrófilos provenientes dos ratos com periodontite. Estes resultados mostram que existe uma pre-ativação (priming) dos neutrófilos circulantes já na fase inicial do desenvolvimento da periodontite, fato que pode estar ligado com a severidade e cronicidade de doenças inflamatórias concomitantes.

Palavras-chave: Periodontite. Neutrófilos. Inflamação. Superóxidos. Peroxidase. Redes extracelulares neutrofílicas. Ratos. 


\begin{abstract}
Sánchez-Vinces S. Evaluation of circulationg polymorphonuclear cell activation in rats with ligature-induced periodontitis. [Masters thesis (Pharmacology)] São Paulo: Instituo de Ciências Biomédicas, Universidade de São Paulo, 2016.

Although it is recognized that periodontal diseases and other oral infections are caused by bacteria, it is, in fact, the patient innate immune system the main responsible for this situation. Neutrophils, The key cells of the innate immune system, are responsible for detecting and eliminating microbial invaders and inducing part of the immune system response. These cells, which are loaded with enzymes and other compounds with strong cytotoxic activity, are also responsible for the damage caused during the prolonged inflammatory phase that occurs when they become hyperactive or chronically active by bacterial stimulus or immunoregulators. Recent data suggest a potential loop of oral-systemic inflammatory activation that is identified by the presence of neutrophil activity products at the sites where the inflammatory process was not initially developed. In this study we evaluated some neutrophil activity markers (anion superoxide production, mieloperoxidase release and formation of neutrophil extracellular traps - NETs), and detected their presence and the diference due to the presence of periodontitis in rats. Periodontitis was induced by placing a subgingival cotton ligature around the lower first molars, and after 7 days, neutrophils were isolated from peripheral blood. Our results show an increase in the amount of circulating neutrophils, as well as the response of these cells obtained from rats with periodontitis to different in vitro stimuli, in comparison with those obtined from Sham animals. Superoxide anion production by circulating neutrophils from rats with peridontitis was higher when stimulated with either forbol-12-mlristate-13-acetate (PMA; $100 \mathrm{nM}$ ) or Zymosan (100 particles/cel). In the case of MPO release, either PMA, zymosa or $\mathrm{N}$ formylmethionyl-leucyl-phenylalanine (fMLP $2 \mu \mathrm{M}$ ) produced greater effects neutrophils from rats with periodontitis. The formation of NETs was also higher in the neutrophils from rats with peridontitis in response to PMA. In addition to the stimulated responses, under basal conditions, MPO release and NET formation were also higher in neutrophils obtained from rats with periodontitis. These results show that circulating neutrophils are pre-activated (primed) even in the initial phase of periodontitis development, a fact that may be related to the severity and chronicity of concomitant inflammatory diseases.
\end{abstract}

Keywords: Periodontitis. Neutróphil. Inflammation. Superoxides. Peroxidase. Neutrophil extracelular traps. Rats. 


\section{LISTA DE FIGURAS}

Figura 1 - Representação em diagrama da geração de espécies reativas de oxigênio necessárias para a formação de "neutrophil extracelular traps". 19

Figura 2 - Representação esquemática dos processos celulares envolvidos na formação de NETs. 21

Figura 3 - Colocação da ligadura 26

Figura 4 - Peso corporal dos grupos de animais Sham e Ligadura 32

Figura 5 - Imagens representativas utilizadas na quantificação da perda óssea alveolar das hemi-mandíbulas. 33

Figura 6 - Efeito da periodontite sobre a distância JCE-COA dos molares das hemimandíbulas do lado direito, dos grupos Sham e Perio 34

Figura 7 - Efeito da periodontite sobre a distância JCE-COA dos molares, hemimandíbulas do lado esquerdo, dos grupos Sham e Perio. 35

Figura 8 - Efeito da indução de periodontite sobre a porcentagem de neutrófilos e linfócitos do total de leucócitos 36

Figura 9 - Efeito da indução de periodontite sobre a produção de ânion superóxido pelos neutrófilos quando estimulados com PMA, fMLP e Zimosan. Comparação com a produção Basal nos grupos Sham e Perio 38

Figura 10 - Efeito da indução de periodontite sobre a produção de ânion superóxido pelos neutrófilos no estado basal e quando estimulados com PMA, fMLP e Zimosan. Comparação entre os grupos Sham e Perio. 
Figura 11 - Efeito da indução de periodontite sobre a atividade da mieloperoxidase pelos neutrófilos quando estimulados com PMA, fMLP e Zimosan. Comparação com a produção Basal nos grupos Sham e Perio................................................................. 42

Figura 12 - Efeito da indução de periodontite sobre a atividade da mieloperoxidase dos neutrófilos no estado basal e quando estimulados com PMA, fMLP e Zimosan. Comparação entre os grupos Sham e Perio

Figura 13 - Efeito da indução de periodontite sobre a produção de NETs pelos neutrófilos quando estimulados com PMA, fMLP e Zimosan. Comparação com a produção Basal.

Figura 14 - Efeito da indução de periodontite sobre a atividade da mieloperoxidase dos neutrófilos no estado basal e quando estimulados com PMA, fMLP e Zimosan. Comparação entre os grupos Sham e Perio. 48 


\section{LISTA DE ABREVIATURAS E SIGLAS}

ACPA Anticorpos anti-proteína citrulinada

AMP Peptídeos antimicrobianos

BPI Proteína bactericida incrementadora de permeabilidade

C5a Proteína do complemento $5^{\underline{a}}$

$\mathrm{CaCl}_{2} \quad$ Cloreto de cálcio

CCL3 Quimiocina C-C Ligando 3

COA Crista do osso alveolar

CXCL1 Quimiocina C-X-C Ligando 1

CXCL2 Quimiocina C-X-C Ligando 2

CXCL3 Quimiocina C-X-C Ligando 3

CXCL8 Quimiocina C-X-C Ligando 8

DNA Ácido desoxirribonucleico

ECOR1 Enzima de restrição de E. coli tipo 1

EDTA Ácido etilendiaminotetraacético

E.P.M Erro padrão médio

Erk Quinase regulada por sinal extracelular

fMLP N-formil-L-metionil-L-leucil-fenilalanina

FPR Receptor de formil peptídeos

GCF Fluido crevicular gengival

GM-CSF Fator estimulante de colónias de macrófagos e granulocitos

GPCR Receptor acoplado à proteína $\mathrm{G}$

$\mathrm{H}_{2} \mathrm{O}_{2} \quad$ Peróxido de hidrogênio

H3 Histona H3

$\mathrm{HClO}$ Ácido hipocloroso

HTAB Brometo de hexadeciltrimetilamonio

IL-1 $\quad$ Interleucina 1 beta

IL-8 Interleucina 8

INF Interferon

JCE Junção cemento-esmalte

LL-37 Peptídeo antimicrobial humano relacionado à catelicidina

LPS Lipopolisacarídeo

MIP1- $\alpha$ Proteína inflamatória de macrófagos 1- $\alpha$ 


$\begin{array}{ll}\text { MPO } & \text { Mieloperoxidase } \\ \mathrm{NaCl} & \text { Cloreto de sódio } \\ \mathrm{NADPH} & \text { Nicotinamida adenina dinucleótido fosfato } \\ \mathrm{NE} & \text { Elastase neutrofílica } \\ \mathrm{NET} & \text { Redes extracelulares neutrofílicas } \\ \mathrm{NF} \text { KB } & \text { Fator nuclear KB } \\ \mathrm{NO} & \text { Óxido nítrico } \\ \mathrm{O}^{*} & \text { Ânion superóxido } \\ \text { PAD4 } & \text { Peptidil arginina deiminase-4 } \\ \text { PAF } & \text { Fator de ativação de plaquetas } \\ \text { PI3K } & \text { Fosfatidilinositol-3-quinase } \\ \text { PKC } & \text { Proteína quinase C } \\ \text { PMA } & \text { Forbol 12-miristato 13-acetato } \\ \text { PMN } & \text { Polimorfonucleares } \\ \text { PR3 } & \text { Proteínase-3 } \\ \text { ROS } & \text { Espécies reativas de oxigênio } \\ \text { SOD } & \text { Superóxido dismutase } \\ \text { SPF } & \text { Livre de patógeno específico } \\ \text { TLR } & \text { Receptor tipo toll } \\ \text { TNF- } \alpha & \text { Fator de necrose tumoral alfa } \\ \text { UF } & \text { Unidade de fluorescência }\end{array}$




\section{SUMÁRIO}

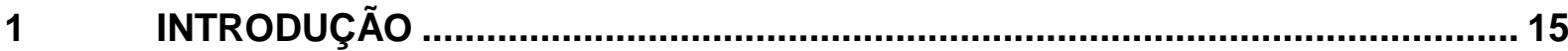

1.1 A periodontite e a resposta inflamatória ........................................................... 15

1.2 Os neutrófilos na periodontite.................................................................. 16

1.3 Componentes ativos dos neutrófilos na inflamação: local x sistêmico ...........17

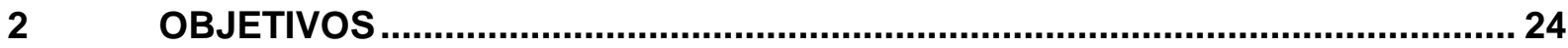

3 MATERIAL E MÉTODOS

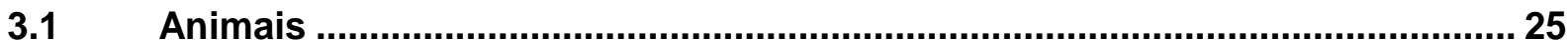

3.2 Indução da periodontite ................................................................................ 26

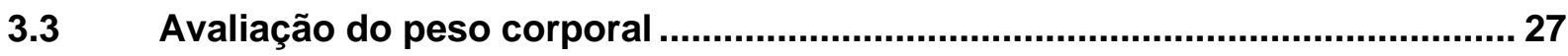

3.4 Análise macroscópica da perda óssea alveolar................................................. 27

3.5 Isolamento de leucócitos polimorfonucleares sanguíneos............................... 27

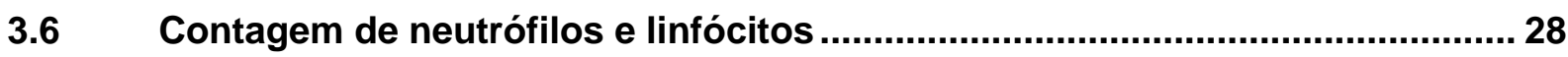

3.7 Análise da ativação neutrofílica ...................................................................... 29

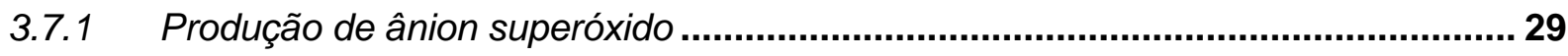

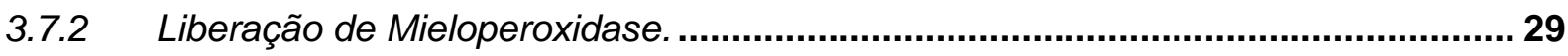

3.7.3 Formação de NETs..................................................................................... 30

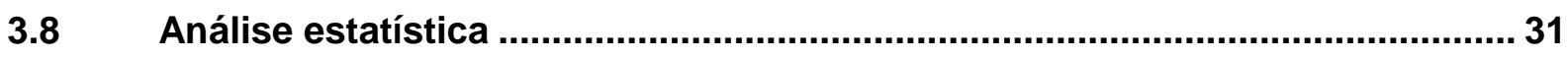

$4 \quad$ RESULTADOS

4.1 Avaliação do peso corporal .............................................................................. 32

4.2 Análise macroscópica da perda óssea alveolar................................................. 33

4.2.1 Perda óssea alveolar das hemi-mandíbulas do lado direito ...................................34

4.2.2 Perda óssea das hemi-mandíbulas do lado esquerdo .......................................... 35

4.3 Isolamento de polimorfonucleares.................................................................... 36

4.4 Contagem celular diferencial: neutrófilos e linfócitos ....................................... 36

4.5 Análise dos indicadores de atividade celular..................................................... 37

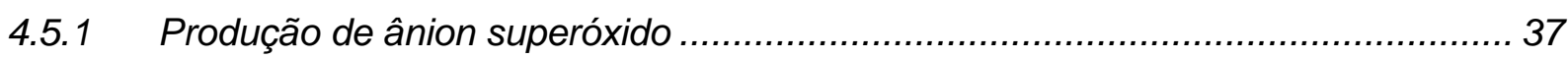

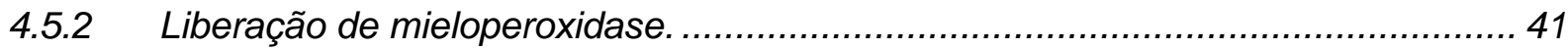




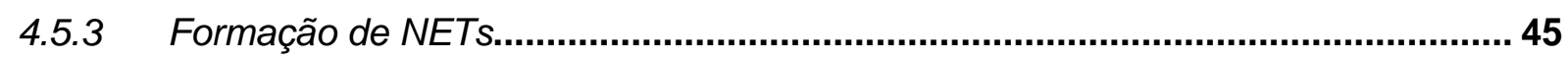

5

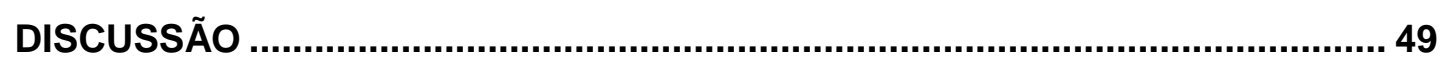

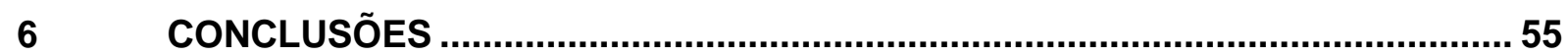

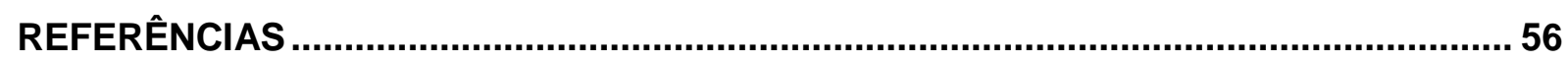


INTRODUÇÃO

\subsection{A periodontite e a resposta inflamatória}

A periodontite é uma doença inflamatória crónica do periodonto, iniciada pela disbiose dentro do biofilme da placa subgengival e que progride por uma desregulação prejudicial da resposta imune-inflamatória do hospedeiro (Hajishengallis, 2014). É altamente prevalente e resulta na perda progressiva do tecido gengival, do ligamento periodontal e do suporte adjacente osso alveolar (Meng et al., 2007). Além disso, a periodontite tem sido associada com doenças sistêmicas, tais como complicações cardiovasculares (Campi et al., 2016; Herrera et al., 2011; Ryder, 2010), artrite reumatoide (Deas et al., 2003), resultados adversos da gravidez (Bender et al. 2006), diabete mellitus e doenças doenças por envelhecimento (Chapple, Genco, 2013).

O biofilme subgengival é complexo e contém diversos patógenos periodontais potenciais. $O$ biofilme contém geralmente uma porção da microbiota comensal anaeróbica gram negativa (-), como também agentes patogênicos oportunistas da cavidade oral, incluindo Porphyromonas gingivalis ( $P$. gingivalis) (Liu et al., 2001). Em resposta a patógenos periodontais, células polimorfonucleares (PMN) liberam sustâncias que, além da atividade de defesa contra patógenos, podem danificar os tecidos do hospedeiro (Brumell et al., 1995). Estas moléculas podem induzir danos oxidativos ao tecido gengival, ligamentos periodontais, e provocar uma reabsorção óssea mediada pela ativação de osteoclastos (Guzik et al., 2011). Os agentes secretados também aumentam a produção de citocinas pró-inflamatórias (p.e. TNF- $\alpha$ ou IL-1 $\beta$ por ativação do fator nuclear $\mathrm{KB}$ ) que contribuem para a piora da doença. Os níveis destas moléculas pró-inflamatórias são frequentemente reduzidos após 0 tratamento da periodontite por remoção do biofilme patógeno (Reeves et al., 2002).

Vale a pena mencionar que nem todos os pacientes são igualmente suscetíveis aos efeitos destrutivos das infecções periodontais, portanto, a periodontite não é causada apenas por uma infecção bacteriana, mas também pode ser associada com a susceptibilidade do hospedeiro (Soehnlein, 2009). A variabilidade na resposta do hospedeiro entre indivíduos contribui de forma significativa para a expressão de 
doenças periodontais (Almeida et al., 1996). Embora as culturas de células humanas tenham sido usadas como modelos úteis para replicar alguns aspectos moleculares do processo da doença periodontal em nível celular, as informações obtidas sobre a complexa resposta do hospedeiro não são suficientes (Chung et al., 2007). Assim, a investigação sobre a resposta do hospedeiro usando animais é criticamente importante na análise da doença periodontal e desenvolvimento de tratamentos melhorados.

As associações entre periodontite e outras condições inflamatórias crônicas são agora bem documentadas. Enquanto vários mecanismos causais poderiam biologicamente explicar estas associações, há alguns indícios que sugerem que a periodontite pode levar à iniciação e manutenção da resposta inflamatória autoimune.

\subsection{Os neutrófilos na periodontite}

Os neutrófilos, os mais abundantes dos leucócitos circulantes em condições normais, são fagócitos antimicrobianos específicos, derivados da linhagem das células mieloides, com capacidade de eliminar agentes patogênicos extracelularmente, fazer a interligação entre os mecanismos de controle inato e adaptativo da resposta imunológica, e ajudam a promover a resolução da inflamação e cicatrização do tecido. Encontrados extensivamente no sulco e epitélio gengival, os neutrófilos são considerados o tipo de célula de proteção chave nos tecidos periodontais (Hoebe et al., 2004). A evidência histológica sugere que os neutrófilos formam uma "parede" entre o epitélio juncional e a placa dentária rica em agentes patogênicos (Schenkein, 2000). Fornecendo mais do que apenas uma função de barreira, esta parede antimicrobiana forma-se com a finalidade de funcionar de duas maneiras: como uma robusta estrutura secretora (espécies reativas de oxigênio [ROS] e proteínas bactericidas) e como um aparelho fagocítico unificado. Em outras palavras, o poder de proteção encontra-se na estrutura sinérgica. No entanto, essa proteção não ocorre sem um custo. Consideráveis dados observacionais, genéticos e experimentais têm estabelecido uma clara associação entre a infiltração de neutrófilos nos tecidos periodontais e a gravidade e progressão de doenças inflamatórias periodontais (Ryder, 2000). 
Na medula óssea, os neutrófilos são transcricional e traducionalmente ativos. Durante este "programa de diferenciação", estão equipados com um grande arsenal de moléculas pré-formadas de sinalização e antimicrobianas (espécies reativas de oxigênio e peptídeos antimicrobianos), armazenados em grânulos (Hattori et al., 2010). Após diferenciação e maturação (14 dias), os neutrófilos entram na circulação como células terminalmente diferenciadas que têm sido considerados transcricionalmente quiescentes. No entanto, dados recentes demonstram que após sua saída da vasculatura para os tecidos infectados ou inflamados, tais como o periodonto, os neutrófilos são submetidos a uma segunda explosão de atividade transcricional, num processo denominado como o "programa de resposta imune". Neste processo, as citocinas e quimiocinas (CCL3, CXCL1, CXCL2, CXCL3, IL1- $\beta$, entre outras) moléculas que dirigem a inflamação ou promovem a cura, são produtos de tradução importantes (Lakschevitz et al., 2015). Embora ainda não tenha sido estabelecida a relevância da atividade genética dos neutrófilos nos tecidos periodontais, é importante notar que o programa de resposta imune torna os neutrófilos periodontais capazes de sintetizar "de novo" fatores que podem influenciar a progressão da doença. Em outras palavras, os neutrófilos periodontais não são funcionalmente dependentes apenas do seu conteúdo granular, como se pensava anteriormente.

\subsection{Componentes ativos dos neutrófilos na inflamação}

Os neutrófilos são fagócitos eficientes e engolfam micróbios em fagossomas que rapidamente se fundem com os grânulos, criando um ambiente no qual os micróbios são expostos a várias enzimas, incluindo a lisozima (que rompe a parede bacteriana), proteases e fosfolipases. Além disso, muitos peptídeos catiônicos, como a proteína bactericida incrementadora da permeabilidade (BPI), defensinas e catelicidinas, são descarregados no fagolisossoma. Simultaneamente, espécies reativas de oxigênio (ROS), como o radical superóxido e o peróxido de hidrogênio, são gerados pelo complexo NADPH oxidase na membrana fagossomal e liberado em seu lúmen. A atividade biológica de muitos destes componentes em determinadas condições in vitro tem sido bem demonstrada, mas a contribuição relativa de cada um 
deles na função dos neutrófilos "in vivo" ainda não foi determinada (Amulic et al., 2012; Nathan, 2006; Borregaard, 2010).

A resposta, vias e produtos dos neutrófilos são variados, mas confluem em algum ponto. De fato, a resposta neutrofílica quanto à produção das redes (ou armadilhas) extracelulares (NETs, do inglês, "neutrophil extracellular traps"; Brinkmann et al, 2004), a qual envolve várias vias importantes, é a resposta mais potente, comprometendo a viabilidade do neutrófilo, e é possível que seja também um indutor da resposta autoimune. O impacto das NETs deriva das atividades antimicrobianas combinadas dos componentes granulares, histonas e algumas proteínas citoplasmáticas. Os eosinófilos e mastócitos, que são granulócitos estreitamente relacionados com os neutrófilos, os granulócitos homólogos em vertebrados inferiores, e mesmo as plantas podem liberar redes extracelulares.

As redes extracelulares dos neutrófilos representam uma recente descoberta estratégia da imunidade inata de confinamento e destruição microbiana. As evidências indicam que as redes extracelulares dos neutrófilos podem ser liberadas tanto a partir de células viáveis como também daquelas desenvolvendo NETose ("neutrophil extracelular traposis", morte com o objetivo de liberar as NETs), compreendendo, no primeiro caso, a maior parte de DNA mitocondrial, e no segundo caso, a maior parte de DNA nuclear e cromatina. A liberação da rede extracelular mitocondrial parece eficaz como estratégia antimicrobiana e tem a vantagem de que as células que respondem permanecem viáveis e o conteúdo nuclear não entra nos tecidos extracelulares, como ocorre na netose, fato que pode ter amplas implicações na cronicidade da resposta ou na resposta autoimune. A liberação letal de NETs, produto de múltiplas e fortes estimulações de diferentes receptores (ver figura 2), e que resulta na liberação de DNA nuclear em conjunto com proteínas histonas e outros componentes nucleares e citoplasmáticos, é mais provável que seja patogênica através da geração de autoanticorpos para elementos citoplasmáticos e antígenos nucleares (por exemplo, antígenos nucleares extraíveis) de neutrófilos introduzidas em tecidos durante a "NETose". Assim, a "netose", como qualquer estratégia de 'último recurso' concebida para causar máximos danos aos micróbios, pode muito bem ser também responsável por dano colateral tecidual substancial e levar a inflamação crônica (Cooper et al., 2012). 
Um passo inicial e importante na produção de NETs por neutrófilos ativados é a geração de ROS após a montagem da NADPH oxidase. Este processo resulta na produção de superóxido e subsequentemente de peróxido de hidrogênio, o qual oxida ions cloreto a ácido hipocloroso $(\mathrm{HClO})$ pela ação catalítica da enzima mieloperoxidase (MPO) (Palmer, Cooper, et al., 2002). A peptidil arginina deiminase4 (PAD4), uma enzima dependente de cálcio, converte resíduos de arginina e metilarginina em citrulina, nas histonas. $O$ processo de citrulinização (p.e. transformação de arginina carregada positivamente para o aminoácido neutro citrulina) causa a perda da atração eletrostática e a consequente decondensação da cromatina nuclear (Wang et al., 2009), o que promove a formação de vesículas entre a membrana nuclear interna e externa e é associada com grânulos neutrofílicos liberando suas enzimas constitutivas, tais como a catelicidina e a proteinase-3 (PR3). As moléculas liberadas ficam associadas à cromatina no momento em que esta entra no citoplasma após desintegração da envoltura nuclear. A colocalização permite ao DNA formar complexos com a catelicidina granular e outros peptídeos antimicrobianos (AMPs), e/ou serino proteases tais como a elastase neutrofílica (NE), MPO, PR3, e a calprotectina (Urban et al., 2009). Os complexos cromatina-proteína finalmente ocupam o espaço citoplásmico antes da ruptura da membrana celular externa do neutrófilo e da extrusão de cadeias extracelulares.

Figura 1 - Representação em diagrama da geração de espécies reativas de oxigênio necessárias para a formação de "neutrophil extracelular traps".

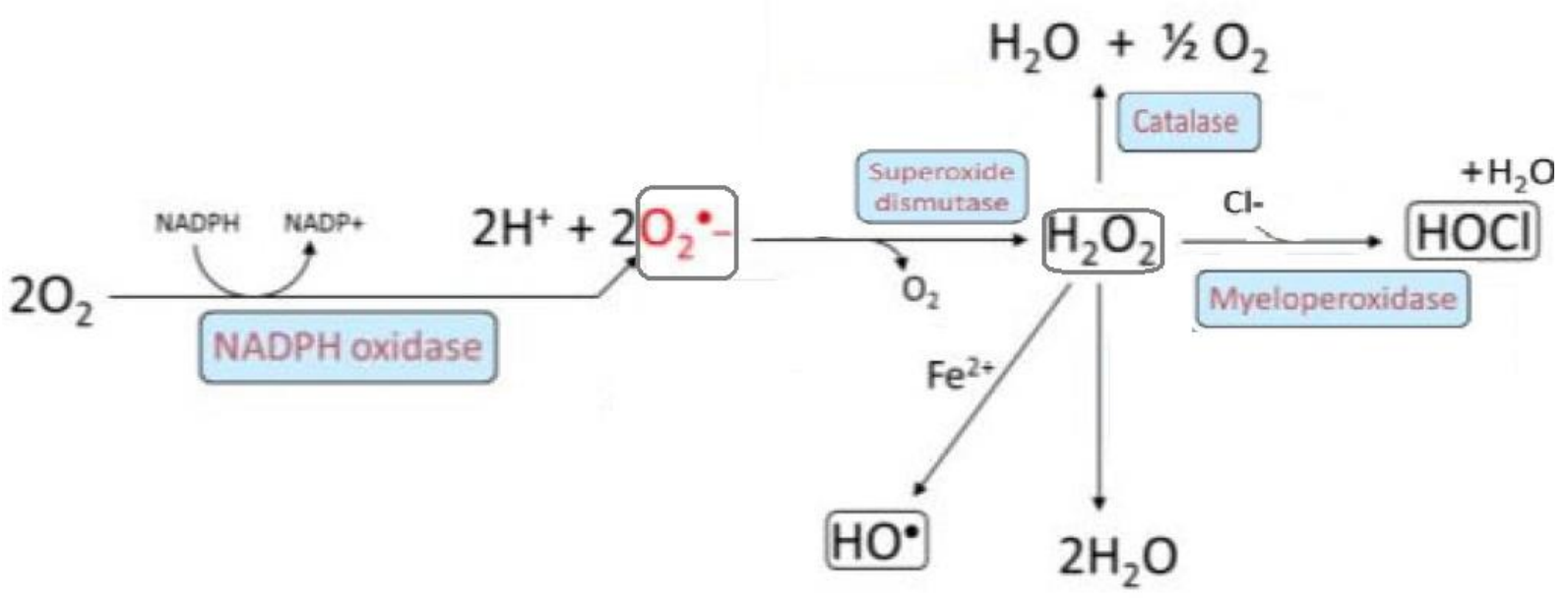

Fonte: Modificado de Mathew et al., 2015. 
O ânion superóxido e um dos principais produtos e precursores da atividade de defesa oxidativa dos neutrófilos, portanto, tem uma grande responsabilidade na resposta prejudicial destes na periodontite. A MPO é uma enzima encontrada nos grânulos intracelulares de neutrófilos e o seu produto, o ácido hipocloroso, é encontrado fora da célula, seja pela liberação dos grânulos ou das NETs. (Dahiya et al., 2016). 
Figura 2 - Representação esquemática dos processos celulares envolvidos na formação de NETs.

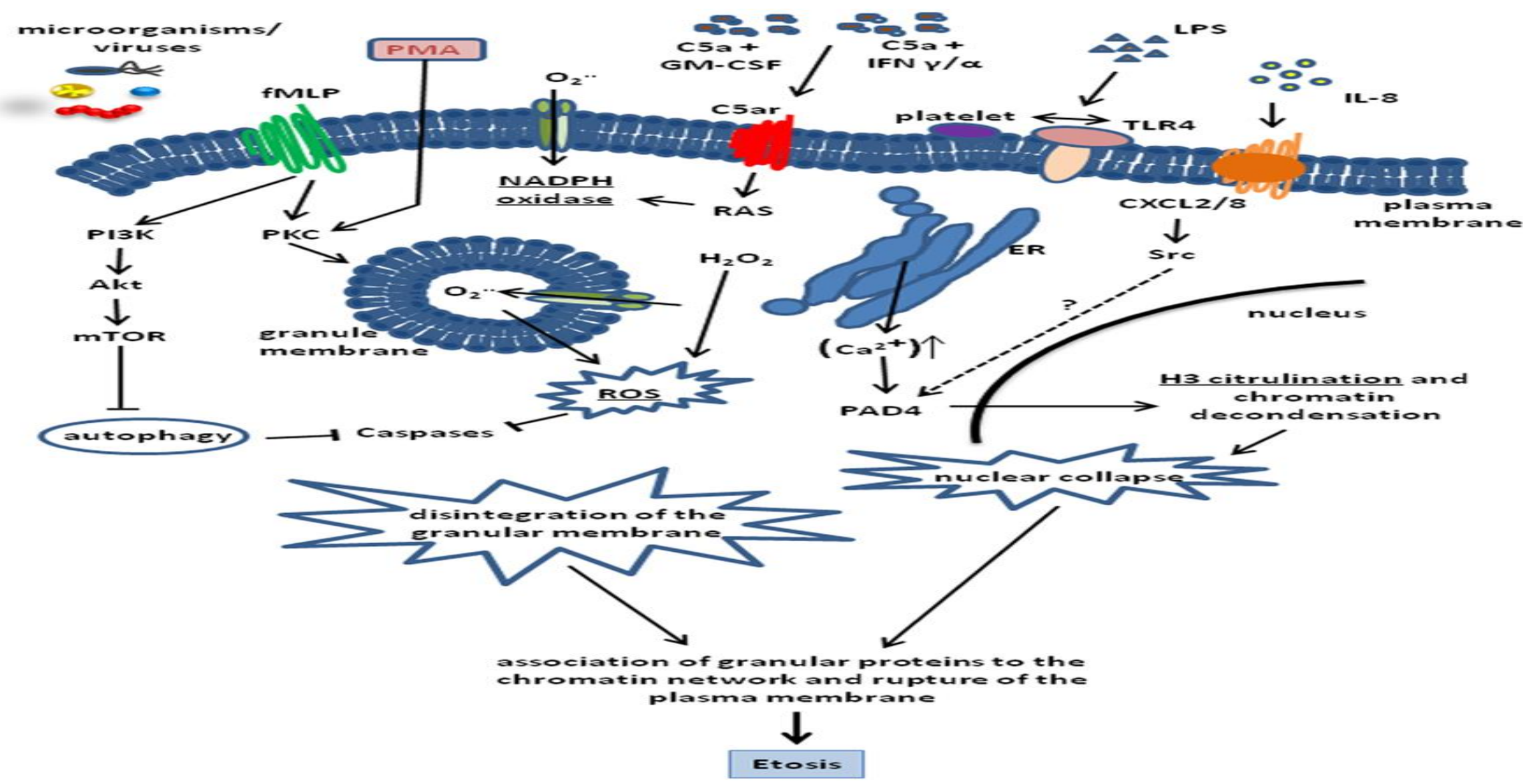

O processo pode ser começado por vários estímulos incluindo, PMA, LPS, C5a + GM-CSF, INF a/y. LPS, baterias e vírus. IL-8 também é capaz de desencadear liberação de NETs pela interação com o receptor CXCL2/8 e pela indução de citrulinização de H3 mediada pela ativação do PAD4 via Src Kinases. A maioria das vias converge na ativação da enzima chave NADPH oxidase. Esta enzima é grandemente ativada pelo PMA e por peptídeos formilados (p.e. o fMLP ativa seu receptor GPC) agindo sobre a PKC. Por outro lado, fMLP bloqueia a autofagia via PI3K (fosfatidilinositol-3-cinace), o qual é capaz de prevenir a NETose. A atividade da NADPH oxidase resulta em produção de ROS e citrulinização de $\mathrm{H} 3$ que resulta em descondensação da cromatina e colapso nuclear. A desintegração da membrana nuclear e a adsorção de proteínas granulares antimicrobianas à cromatina descondensada é o passo final da Netose que precede a liberação das NETs no espaço extracelular após ruptura da membrana plasmática.

Fonte: Goldman and Medina 2013 
Como indicado na Figura 2, os compostos que estimulam a resposta do neutrófilos são variados. A maioria dos autores que estudam a biologia das NETs usam forbol 12-miristato 13-acetato como um estímulo de controle positivo para a ativação da NADPH oxidase e a subsequente formação das armadilhas extracelulares dos neutrófilos. O forbol 12-miristato 13-acetato (PMA) é estrutural e funcionalmente semelhante ao diacilglicerol, - molécula segundo mensageiro natural e intracelular de sinalização lipídica- que fisiologicamente ativa de maneira direta a proteína quinase C. A proteína quinase $\mathrm{C}$, em seguida, orquestra a montagem das subunidades de NADPH-oxidase na membrana vacuolar e inicia a geração de superóxido. O PMA tem a vantagem de ativar diretamente a proteína quinase $C$ independente de qualquer ligação com receptores de superfície do neutrófilo, e ainda evitando o processo de fagocitose. Tem sido relatado que cerca de $1 / 3$ dos neutrófilos isolados a partir de sangue venoso humano e ativados por PMA produzem redes extracelulares "in vitro" (Fuchs et al., 2007), em contraste com $80 \%$ dos neutrófilos expostos a "priming" pelo GM-CSF (Granulocyte-macrophage colony-stimulating fator) e subsequente estímulo de curta duração com C5a ou lipopolissacárido (Yousefi et al., 2009).

Peptídeos N-formilados como a fMLP (N-formil-L-metionil-L-leucil-fenilalanina) desempenham um papel importante como potentes quimioatraentes. Este composto mimetiza os efeitos de oligopeptídeos $n$-formilados que se originam a partir de qualquer proteína bacteriana ou mitocondrial degradada. O receptor do peptídeo Nformilado é acoplado a proteína G (receptor de formil peptídeos: FPR1 ou FPR2) e medeia reações pró ou anti-inflamatórias nos neutrófilos humanos e outros tecidos, tais como a produção de ROS ou a inibição da autofagia (Li, Ye, 2013).

O zimosan é um composto fagocitável, preparado a partir de paredes celulares de leveduras e consiste em complexos de proteínas e hidratos de carbono que são reconhecidos pelo TLR2. Ele é utilizado para induzir inflamação experimental estéril. O zimosan estimula granulócitos para gerar superóxido mediante a ativação da fosfolipase $A_{2}$ citosólica, produção de ácido araquidônico e apertura de canais de prótons, com posterior regulação por Erk 1/2 (Sheppard et al., 2005).

Mediadores inflamatórios derivados do hospedeiro, tais como as citocinas pró-

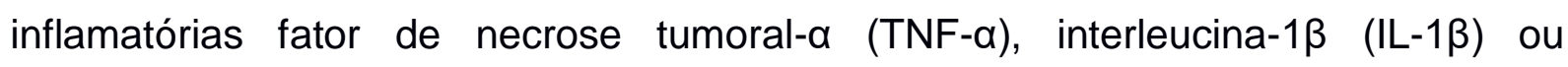
interleucina-8 (IL-8), também tem sido reportados como indutores da geração de NETs 
(Keshari et al. 2012). Experimentos "ex vivo" usando neutrófilos periféricos mostraram que o LL-37, um peptídeo antimicrobial relacionado à catelicidina, pode induzir diretamente a produção de NETs, mas pode também incrementar a liberação de NETs em resposta a bactérias não patogénicas (Neumann et al., 2014). LL-37 tem sido encontrado em níveis significativamente elevado no fluido crevicular gengival (GCF) de pacientes com periodontite (McCrudden et al. 2013), o qual, em adição às bactérias presentes, pode prover um estímulo para a liberação das NETs.

Outros estímulos para a liberação de NETs identificados na literatura compreendem (Cooper et al., 2013; Hirschfeld et al., 2015; Palmer et al., 2015):

Componentes derivados de bactérias: Glicose oxidase, Lipopolisacárido, Nformilmetionina-leucil-fenilalanina (fMLP), Lipofosfoglicano, leucotoxina GH, Pantonvalentine leucocidina, enolase de superfície estreptocócica, invasina proteína adesiva.

Componentes derivados do hospedeiro: Plaquetas e fator ativador de plaqueta (PAF), óxido nítrico (NO), anticorpos, fator de necrose tumoral- $\alpha$, interleucina-1 $\beta$ e -8, GM-CSF+C5a e LPS, LL-37.

Estímulos Ex vivo: PMA, ácido hipocloroso ( $\mathrm{HOCl})$, estatinas.

Em resumo, a periodontite surge por causa de uma resposta exacerbada do hospedeiro a um biofilme patogênico que se manifesta em indivíduos susceptíveis, e os neutrófilos são o tipo de célula imunológica mais importante envolvida na resposta inflamatória periodontal. Por conseguinte, é razoável especular que perturbações na função de neutrófilos podem estar presentes dependendo do estado periodontal do hospedeiro (Meng et al., 2007). 


\section{OBJETIVOS}

- Estudar o grau de pre-ativação presente em neutrófilos circulantes de ratos com periodontite induzida por ligadura na fase inicial da doença, pela avaliação de diferentes respostas in vitro dos neutrófilos.

\section{Estratégias}

- Verificar o efeito da periodontite nas proporções de células brancas circulantes (neutrófilos e linfócito).

- Avaliar e quantificar marcadores de atividade neutrofílica produzida por os estímulos PMA (ativador da PKC sem receptor de membrana), fMLP (peptídeo n-formilado ativador do FPR) e o zimosan (partícula fagocitável): Produção de ânion superóxido, liberação de MPO e formação de NETs) em neutrófilos isolados de sangue de ratos com periodontite (7 dias) e Sham estimulados com PMA, fMLP e Zimosan. 


\section{MATERIAL E MÉTODOS}

\subsection{Animais}

Ratos Wistar SPF de 6-8 semanas de vida (200-250 g) provenientes do Biotério Central do Instituto de Ciências Biomédicas da Universidade de São Paulo, foram mantidos em grupos de cinco animais por gaiola e receberam água e ração padrão $\mathrm{ad}$ libitum e com temperatura controlada de $22 \pm 2{ }^{\circ} \mathrm{C}$. Todos os procedimentos empregados no presente estudo foram aprovados pela Comissão de Ética no Uso de Animais (CEUA) do Instituto de Ciências Biomédicas da USP (n. 170, livro 2, pág. 113).

Os ratos foram separados em 2 grupos experimentais: Periodontite (Perio), os quais tiveram a ligadura por 7 dias, e Sham (com a ligadura retirada imediatamente após colocada).

Todos os experimentos foram realizados após anestesia dos animais pela administração intraperitoneal (i.p.) de uma mistura de cetamina $(80 \mathrm{mg} / \mathrm{kg})$ e xilazina (20 mg/kg). 


\subsection{Indução da periodontite}

Os animais foram aclimatizados às condições do biotério durante 07 dias.

Após anestesia, um fio de sutura de algodão $\mathrm{N}^{\circ} 3-0$ foi colocado sobmarginalmente ao redor do primeiro molar inferior esquerdo e direito dos animais do grupo Perio. Os ratos do grupo Sham foram submetidos ao mesmo procedimento, mas a ligadura foi removida logo em seguida a sua colocação.

Após uma semana da indução da periodontite, os animais foram anestesiados para a coleta de sangue da veia cava inferior e em seguida submetidos a eutanásia por decapitação. O protocolo foi realizado segundo o indicado por Sallay em 1982.

Figura 3- Colocação da ligadura.

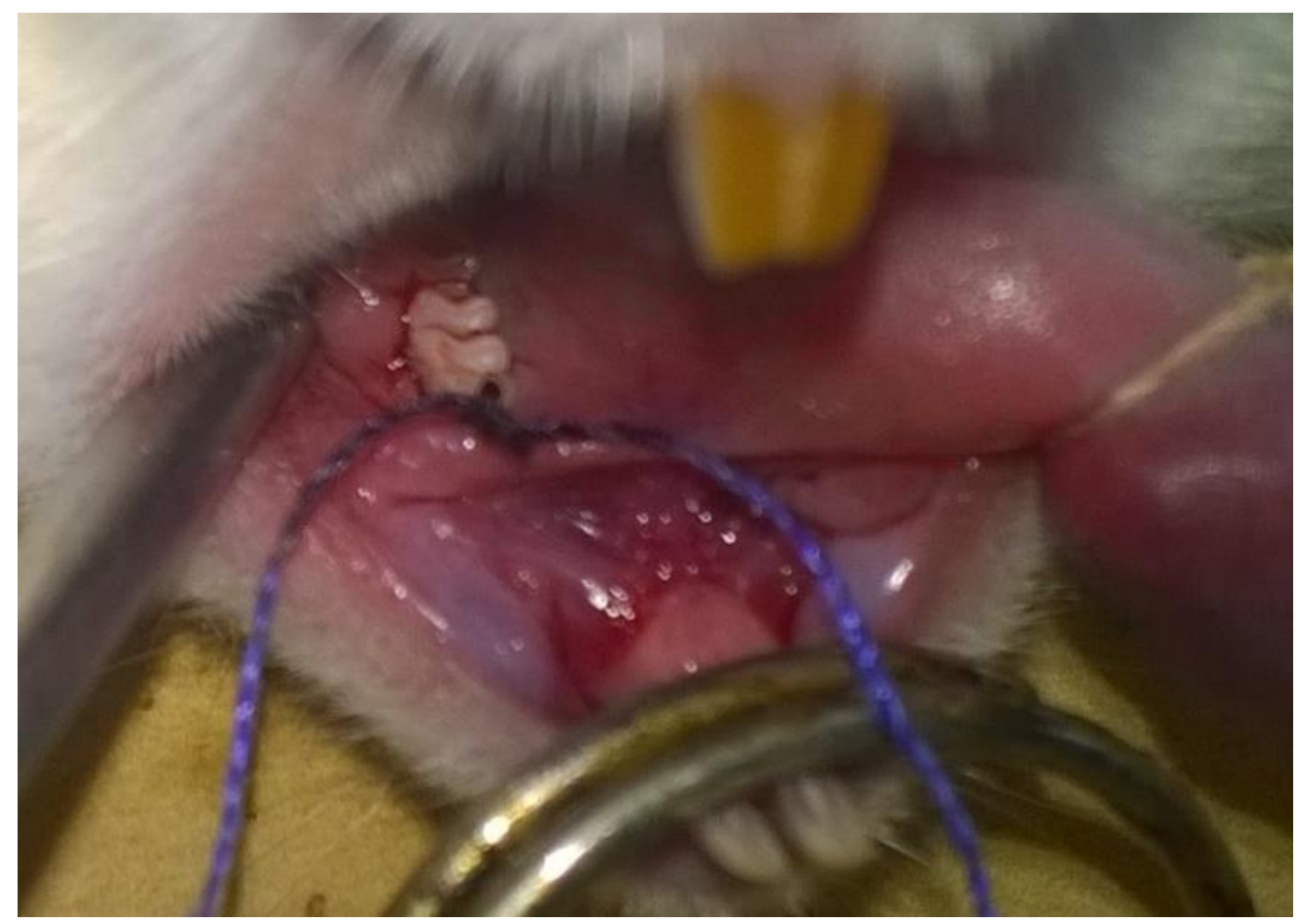

Colocação do fio de sutura usado como ligadura no primeiro molar direito. 


\subsection{Avaliação do peso corporal}

O peso corporal foi determinado antes da indução da periodontite, e depois de sete dias os ratos foram novamente pesados, antes de serem submetidos a eutanásia.

Os resultados estão expressos como ganho ponderal, calculado como a diferença em gramas $(\mathrm{g})$ entre o valor do peso final e do inicial.

\subsection{Análise macroscópica da perda óssea alveolar.}

No sétimo dia, as mandíbulas foram retiradas e com ajuda de uma espátula, o tecido gengival foi parcialmente removido da mandíbula e em seguida as hemimandíbulas (lado direito e esquerdo) foram separadas.

As amostras foram imersas durante sete horas em peróxido de hidrogênio $30 \%$, para que os tecidos moles restantes fossem removidos completamente. Com o propósito de distinguir o osso dos tecidos dentários, as hemi-mandíbulas foram coloridas por imersão em solução de azul de metileno à $1 \%$ durante 25 minutos. A seguir, as hemi-mandíbulas foram escaneadas (HP Scanjet 3670) com resolução de 1200 dpi e as medições foram realizadas por um examinador que desconhecia a origem das amostras utilizando o software de processamento de imagem, Image $\mathrm{J}$ 1.49. A perda óssea alveolar foi quantificada pela somatória, em milímetros $(\mathrm{mm})$, das distâncias compreendidas entre a crista do osso alveolar (COA) e a junção cementoesmalte (JCE) na face lingual de todas as raízes de cada um dos três molares (isto é, nas três raízes dos primeiros molares e nas duas raízes dos segundos e terceiros molares; Crawford et al., 1978).

\subsection{Isolamento de leucócitos polimorfonucleares sanguíneos}

O método empregado em nosso laboratório foi adaptado do descrito por Franco-Penteado (Franco-Penteado 2001). Com os ratos anestesiados, aproximadamente $10 \mathrm{~mL}$ de sangue foram coletados da veia cava inferior em tubos cônicos de plástico contendo $10 \%$ uma solução de citrato de sódio $3,7 \%$. Primeiramente as hemácias foram separadas misturando-se o sangue coletado com 
o mesmo volume de uma solução de Dextran 6\% em salina (DEXTRAN T500, 170320-02, Amersham Pharmacia Biotech AB, Sweden) deixado em repouso por 40-60 min à temperatura ambiente. A camada superior (que continha as células brancas) foi transferida para outro tubo e centrifugada a $300 \mathrm{~g}$ a $4{ }^{\circ} \mathrm{C}$ durante 10 min e o pellet formado foi lavado em $3 \mathrm{ml}$ de solução Hanks e em seguida centrifugado por mais 10 min adicionais. O pellet foi novamente ressuspendido em $3 \mathrm{ml}$ de solução Hanks e adicionado cuidadosamente sobre o mesmo volume de Ficoll 1077 (Amersham Pharmacia) e centrifugado a $400 \mathrm{~g}$ (1325 rpm) durante 30 min para separar as células polimorfonucleares por gradiente de densidade descontínuo (Siemsen et al., 2014). O sobrenadante foi desprezado e o "pellet" submetido à lise hipotônica das hemácias pela adição de $3 \mathrm{ml}$ de água destilada por $25 \mathrm{seg}$ e em seguida $1 \mathrm{ml}$ de $\mathrm{NaCl} 3,6 \%$. A suspensão celular foi então centrifugada a $300 \mathrm{~g}$ durante $10 \mathrm{~min}$ e o pellet posteriormente ressuspendido em $1 \mathrm{ml}$ de solução Hanks para posterior contagem total das células. As células foram ajustadas para $2 \times 10^{6} \mathrm{cel} / \mathrm{ml}$. A contagem total das células foi realizada em câmara de Neubauer utilizando-se $10 \mu \mathrm{l}$ da suspensão de células e adicionou-se $190 \mu \mathrm{l}$ de corante Turk (0,0005\% de cristal violeta em ácido acético 4\%). A contagem diferencial foi realizada preparando-se lâmina com $100 \mu \mathrm{l}$ de suspensão celular e em seguida coradas com corante May-Grünwald. As análises de ativação de neutrófilos foram realizadas somente com suspensões de PMNs com pureza acima de $85 \%$.

\subsection{Contagem de neutrófilos e linfócitos}

Uma alíquota de $20 \mu \mathrm{L}$ do sangue de cada amostra coletada foi utilizada para contagem diferencial automatizada utilizando o contador hematológico Genius KT 6200. Os resultados foram expressos em porcentagem de leucócitos. 


\subsection{Análise da ativação neutrofílica}

\subsubsection{Produção de ânion superóxido}

A estimação da produção de ânion superóxido in vitro está baseada na quantificação espectrofotométrica da redução do ferricitocromo c para ferrocitocromo c mediada pelo ânion superóxido, segundo descrito originalmente por McCord e Fridovich (1969). Uma suspensão de $2 \times 10^{6}$ células $/ \mathrm{ml}$ em meio Hanks pH 7.4 contendo $\mathrm{CaCl}_{2} 1 \mathrm{mM}(175 \mu \mathrm{l})$ foi incubada na presença de $25 \mu \mathrm{l}$ de ferricitocromo $\mathrm{c}$

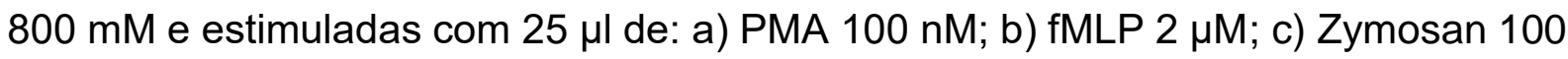
partículas/cel., na presença e na ausência de $25 \mu$ l de superóxido dismutase 1200 $\mathrm{U} / \mathrm{ml}$. A presença de superóxido dismutase (SOD) no meio de incubação inibe a formação de ferrocitocromo c (controle negativo). Em paralelo, também foi processado um tubo sem estímulo (Basal). Após 60 minutos a $37^{\circ} \mathrm{C}$, as células foram separadas por centrifugação (300 g) e as absorbâncias dos sobrenadantes foram lidas a 550 nm e convertidas para nmols de ânion superóxido gerados considerando-se um coeficiente de extinção molar de $29500 \mathrm{M}^{-1} \mathrm{~cm}^{-1}$ para o ferrocitocromo c (CondinoNeto e al., 1993). Os resultados foram expressos em nmol de ânion superóxido por $10^{6}$ células.

\subsubsection{Liberação de Mieloperoxidase.}

Neste ensaio, o $\mathrm{H}_{2} \mathrm{O}_{2}$ oxida o dihidocloreto de o-dianisidina (convertendo-o em um composto colorido com máximo de absorção em $460 \mathrm{~nm}$ ) catalisado pela MPO liberada da suspensão de neutrófilos com detergente tampão brometo de hexadeciltrimetilamonio (HTAB). Assim, a velocidade de oxidação da o-dianisidina é proporcional à quantidade de MPO presente na amostra (Bradley et al., 1982).

Após estimulação dos neutrófilos como descrito acima, as amostras de sobrenadantes (contendo a MPO liberada) e da suspensão total (MPO presente no pellet mais o sobrenadante) foram mantidas em banho de gelo. Foram adicionados $100 \mu \mathrm{l}$ de tampão contendo o detergente HTAB e a seguir foram sonicadas durante 20 segundos a fim de inibir a catalase endógena, as amostras foram mantidas em 
estufa a $60{ }^{\circ} \mathrm{C}$ por 2 horas. Depois, as amostras foram centrifugadas em microcentrífuga Eppendorf (300 g) e os sobrenadantes obtidos foram submetidos à análise da atividade da MPO.

Dez $\mu \mathrm{l}$ de sobrenadante foram adicionados a $200 \mu \mathrm{l}$ de solução de dihidrocloreto de o-dianisidina em uma placa de 96 poços. A medida da absorbância foi realizada a $460 \mathrm{~nm}$ e registrada em intervalos de $15 \mathrm{seg}$ por 5 minutos.

A atividade da MPO nas amostras foi calculada em relação a cada amostra conforme a fórmula: MPO $(\mathrm{U})=\mathrm{Vmax} / \mathrm{s} / 0,0113$. Uma unidade $(\mathrm{U})$ de atividade MPO é definida como aquela capaz de degradar $1 \mu \mathrm{mol}$ de $\mathrm{H}_{2} \mathrm{O}_{2} / \mathrm{min}$.

Para cada amostra, os resultados foram calculados como a porcentagem de MPO liberada no sobrenadante em relação à MPO total (pellet mais sobrenadante).

\subsubsection{Formação de NETs.}

Este método baseia-se na quantificação fluorimétrica de fragmentos de dsDNA conjugado com o corante QuantiFluor (SigmaAldrich). Os fragmentos são produzidos pela atividade da ECOR1 sobre as cadeias de DNA liberadas nas NETs (livre ou ancorada).

Após o isolamento dos neutrófilos, a suspensão celular foi ajustada a $2 \times 10^{6} \mathrm{cel} / \mathrm{mL}$ e estimulada com PMA, fMLP e zimosan, como indicado nos métodos anteriores. A seguir, foi adicionado a cada amostra (250 $\mu \mathrm{L})$ a enzima ECOR1 (20 U/mL), foram misturadas suavemente e, logo, centrifugadas (300 g por 10'). Após centrifugação o sobrenadante foi separado para posterior análise. Foi adicionado ácido etilendiaminotetraacético (EDTA $50 \mu \mathrm{M})$ para deter a atividade da enzima de restrição. $100 \mu \mathrm{L}$ da suspensão final foram transferidos a placas de 96 poços e misturados com $100 \mu \mathrm{L}$ do reagente QuantiFluor (1 x). A quantificação dos fragmentos de DNA foi feita por fluorimetria (exitação: $490 \mathrm{~nm}$, emissão: 510/570 nm) e os resultados foram expressos em unidades de fluorescência (UF). 


\subsection{Análise estatística}

Os resultados foram expressos como média \pm E.P.M. As diferenças entre os grupos experimentais foram analisadas pelo teste $t$ de Student para amostras não pareadas, utilizando o programa GraphPad Prism v.6. Diferenças entre os grupos com valores de $\mathrm{P}<0,05$ foram consideradas estatisticamente significativas. 


\section{$4 \quad$ RESULTADOS}

\subsection{Avaliação do peso corporal}

Os grupos Periodontite (Perio) e Sham tiveram medias de pesos corportais semelhantes (Sham: $290 \pm 11 \mathrm{~g}$, Perio: $285 \pm 13 \mathrm{~g}$ ). Após sete dias da colocação da ligadura, o grupo Perio apresentou menor aumento ponderal de peso quando comparado ao grupo Sham (Sham: $27,75 \pm 1,17$ vs. Perio 22,71 $\pm 1,07 ; \mathrm{P}<0,01$; Figura 4).

Figura 4- Peso corporal dos grupos de animais Sham e Ligadura

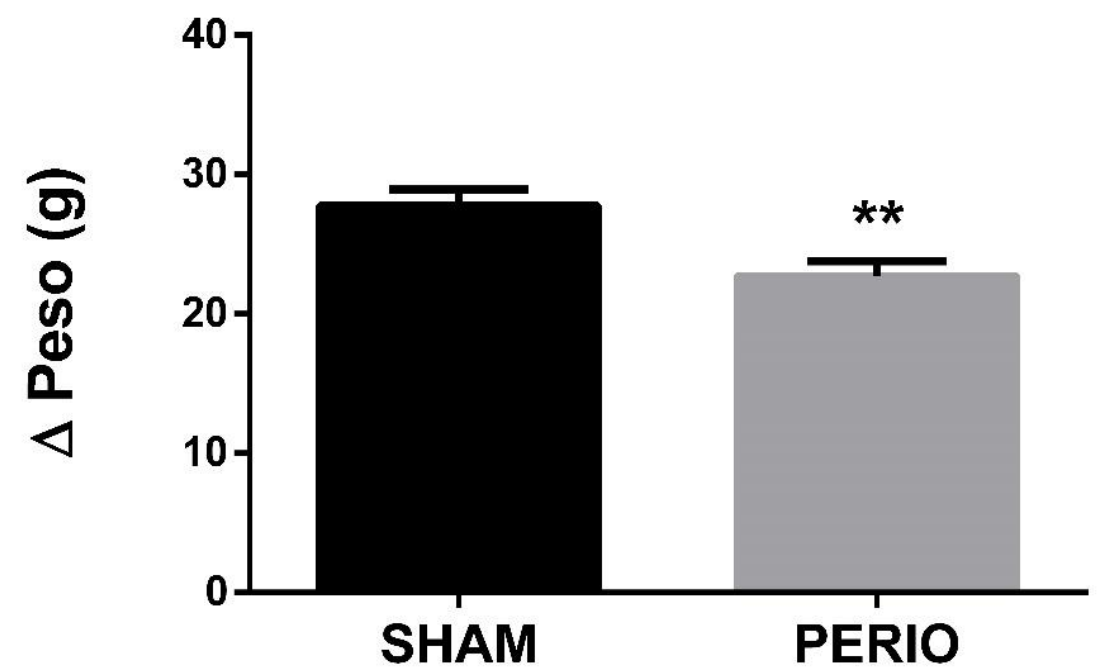

Peso corporal dos grupos de ratos Sham e com Perio ( $n=33$ e 31 ratos/grupo, respectivamente) $P<0,01$ vs. Sham, de acordo com o teste $t$ de Student para dados não-pareados. 


\subsection{Análise macroscópica da perda óssea alveolar.}

Figura 5- Imagens representativas utilizadas na quantificação da perda óssea alveolar das hemi-mandíbulas.

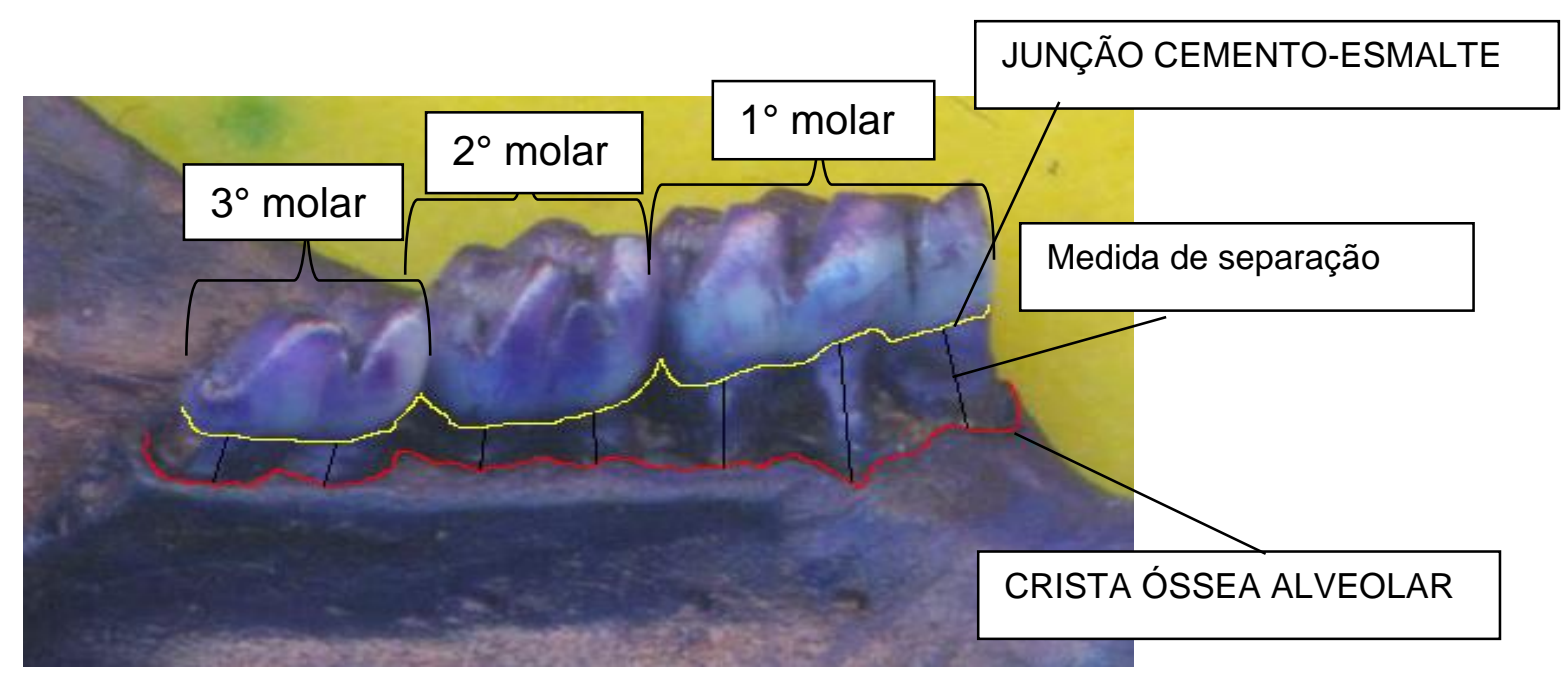

Análise de perda óssea para hemi-mandíbula do lado esquerdo. Identificação dos dentes molares e coloração com azul de metileno. Delimitação da JCE, em amarelo, e da COA, em vermelho. As medidas foram realizadas entre a JCE e COA, demonstradas através das linhas pretas verticais, grupo Perio. 


\subsubsection{Perda óssea alveolar das hemi-mandíbulas do lado direito.}

Como apresentado na Figura 6, o grupo Perio apresenta aumento significativo da distância $(\mathrm{mm})$ entre JCE e COA dos molares, primeiro molar (Sham: 2,58 $\pm 0,04$ vs. Perio: $2,80 \pm 0,02, P<0,001$, painel $A$ ), segundo molar (Sham: 0,88 $\pm 0,01$ vs. Perio: $1,01 \pm 0,03, P<0,01$, painel B) e terceiro molar (Sham: 0,82 $\pm 0,02$ vs. Perio: $0,87 \pm 0,02$, $P<0,01$, painel $C)$, das hemi-mandíbulas do lado direito, quando comparados com o grupo Sham.

Figura 6- Efeito da periodontite por ligadura durante 07 dias sobre a distância JCECOA dos molares das hemi-mandíbulas do lado direito, dos grupos Sham e Perio.
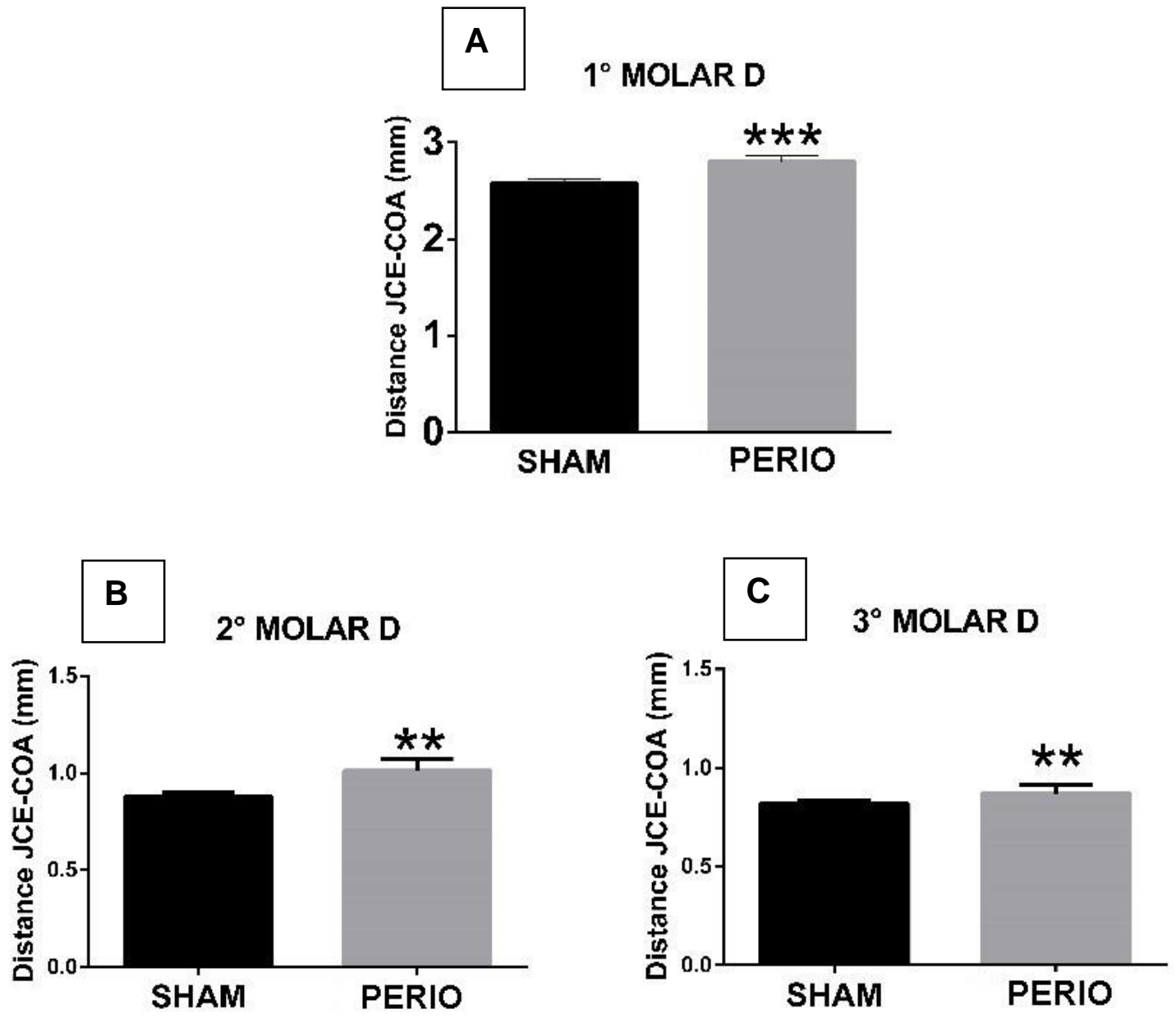

Comparação das distâncias JCE-COA do primeiro molar (painel A), segundo molar (painel B), terceiro molar (painel C), das hemi-mandíbulas do lado direito, grupos de animais Sham e Ligadura $(n=9$ ratos/grupo). ${ }^{* *} \mathrm{P}<0,01 \mathrm{e}^{* * *} \mathrm{P}<0,001$ vs. Sham, de acordo com o teste $t$ de Student para dados nãopareados. 
4.2.2 Perda óssea das hemi-mandíbulas do lado esquerdo.

Como observado na Figura 7, o grupo Perio apresenta aumento estatisticamente significativo da distância $(\mathrm{mm})$ entre a JCE e COA dos molares, primeiro molar (Sham:2,26 0.02963 vs. Perio: $2.57 \pm 0.05058, P<0,001$, painel A), segundo molar (Sham: $0.8867 \pm 0.01581$ vs. Perio: $0.971 \pm 0.02043, P<0,01$, painel B) e terceiro molar (Sham: $0.7219 \pm 0.03593$ vs. Perio: $0.8582 \pm 0.02155, P<0,01$, painel C), das hemi-mandíbulas do lado esquerdo, quando comparados com grupo de animais Sham.

Figura 7- Efeito da periodontite por ligadura durante 07 dias sobre a distância JCECOA dos molares, hemi-mandíbulas do lado esquerdo, dos grupos Sham e Perio.
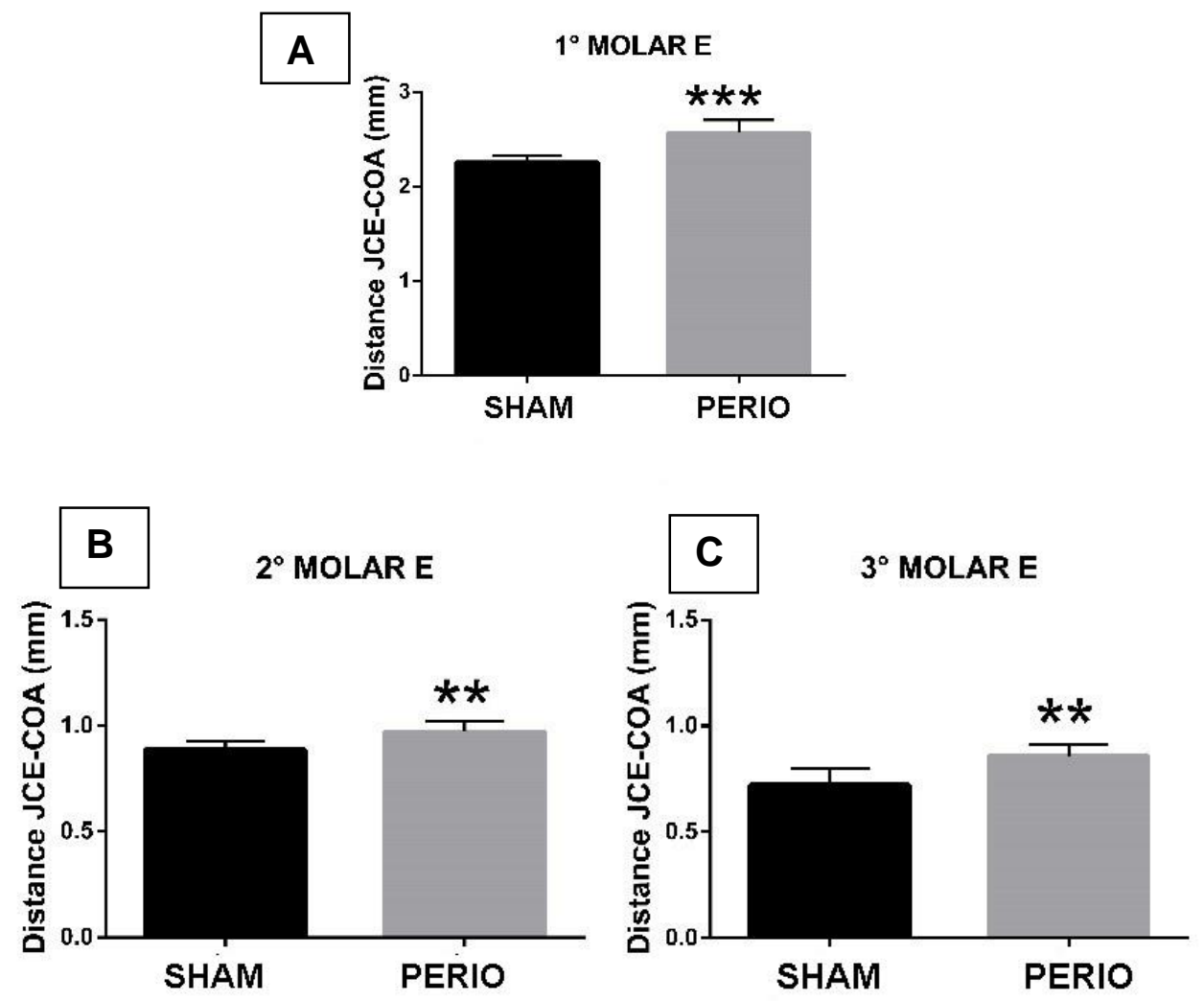

Comparação das distâncias JCE-COA do primeiro molar (painel A), segundo molar (painel B), terceiro molar (painel C), das hemi-mandíbulas do lado esquerdo, grupos de animais Sham e Ligadura ( $n=7$ ratos/grupo). ${ }^{* *} P<0,01$ e ${ }^{* *} P<0,001$ vs. Sham, de acordo com o teste t de Student para dados nãopareados. 


\subsection{Isolamento de polimorfonucleares}

De acordo com nossas contagens totais, observamos que a suspensão de polimorfonucleares continha uma média de $92 \%$ de neutrófilos. Em seguida então, processamos 0 isolamento de neutrófilos circulantes dos ratos com periodontite (7 dias) e Sham para a dosagem da produção de ânion superóxido, da liberação de mieloperoxidase e da formação de NETs.

\subsection{Contagem celular diferencial: neutrófilos e linfócitos}

As contagens mostram um aumento na porcentagem de neutrófilos no grupo com ligadura (Sham: $19.82 \pm 0.9069$; Perio: $30.23 \pm 1.946, \mathrm{P}<0,01)$. Esse aumento na porcentagem de neutrófilos apresenta paralelamente uma diminuição da porcentagem de linfócito (Sham: $74.96 \pm 1.721$; Perio: $64.3 \pm 2.556, \mathrm{P}<0,01$ ) no grupo com ligadura, já que a média indicada pela literatura é de $20-24 \%$ de neutrófilos do total de células brancas em ratos.

Figura 8 - Efeito da indução de periodontite sobre a porcentagem de neutrófilos e linfócitos do total de leucócitos, obtidos do sangue total. Comparação entre o grupo com ligadura e o grupo Sham.
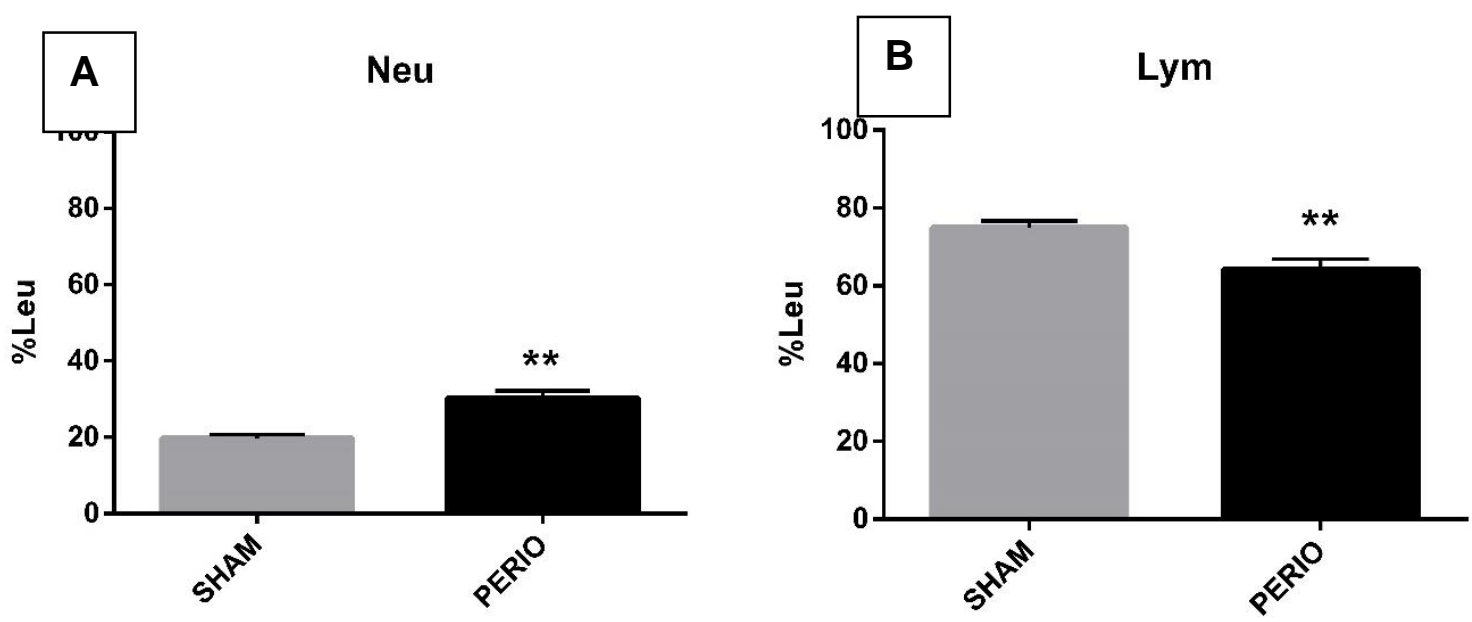

Efeito da ligadura em ratos na porcentagem de linfócitos: neutrófilos (painel A) e linfócitos (painel B), grupos de animais Sham e Periodontite ( $n=5$ ratos/grupo). ${ }^{*} P<0,01$ vs. Sham, de acordo com o teste t de Student para dados não-pareados. 


\subsection{Análise dos indicadores de atividade celular}

\subsubsection{Produção de ânion superóxido}

Nossos resultados mostram que os estímulos PMA (Sham: $2.964 \pm 0.3218$; Perio: $4.351 \pm 0.2759$ ), fMLP (Sham: $0.5957 \pm 0.04521$; Perio: $0.5824 \pm 0.03749$ ) e zimosan (Sham: $0.5640 \pm 0.06271$; Perio: $0.8323 \pm 0.03743$ ) aumentaram a geração de ânion superóxido em ambos grupos experimentais analisados quando comparados com a medida basal (Sham: $0.3743 \pm 0.04430$; Perio: $0,37 \pm 0,04)$, sendo que o PMA é o estímulo que promove um maior aumento dessa geração. Os resultados foram expressos como $\mathrm{nmol} \mathrm{O}_{2}{ }^{*} / 10^{6} \mathrm{cel}$ (Figura 9). 
Figura 9- Efeito da indução de periodontite sobre a produção de ânion superóxido pelos neutrófilos quando estimulados com PMA, fMLP e Zimosan. Comparação com a produção Basal nos grupos Sham e Perio.
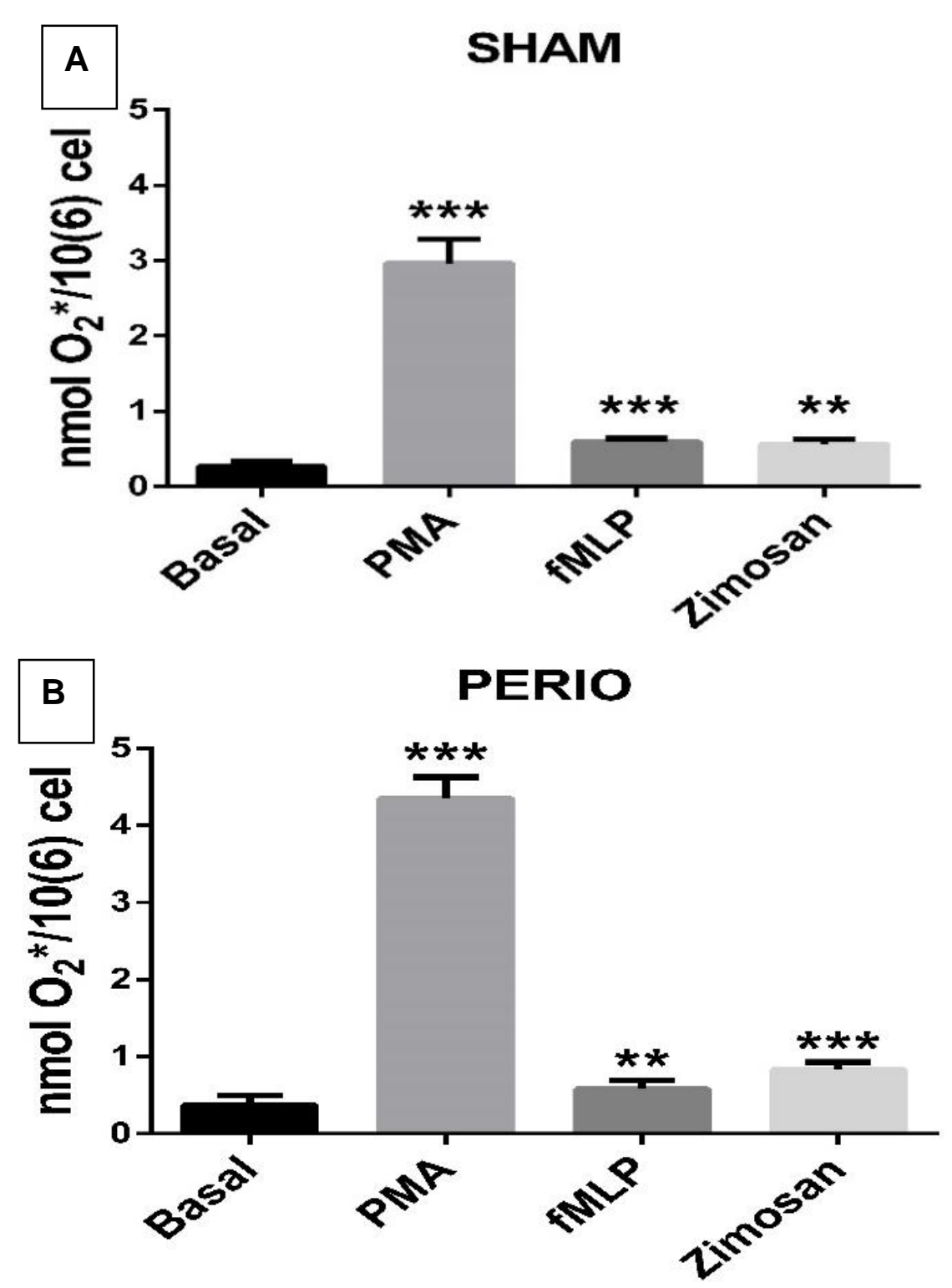

Efeito da ligadura em ratos na produção de ânion superóxido. Painel A: grupo Sham estimulado com PMA $(P<0,001 ; n=7)$, fMLP $(P<0,001 ; n=8)$ e Zimosan $(P<0,01 ; n=9)$ quando comparado com o Basal $(n=7)$. Painel B grupo Perio estimulado com PMA $(P<0,001 ; n=7)$, fMLP $(P<0,01 ; n=8)$ e Zimosan $(P<0,001 ; n=7)$ quando comparado com o Basal $(n=8)$, de acordo com o teste ANOVA uma via seguido pelo test de Dunnet. 
A geração de ânion superóxido dos neutrófilos provenientes de animais do grupo Perio não é estatisticamente diferente daquela observada em animais do grupo Sham no estado basal e quando estimulado com fMLP. No entanto, a geração de ânion superóxido quando estimulado por PMA e Zimosan é estatisticamente maior nos neutrófilos provenientes dos animais do grupo Perio em relação àquela dos animais do grupo Sham. (Figura 10). 
Figura 10- Efeito da indução de periodontite sobre a produção de ânion superóxido pelos neutrófilos no estado basal e quando estimulados com PMA, fMLP e Zimosan. Comparação entre os grupos Sham e Perio.
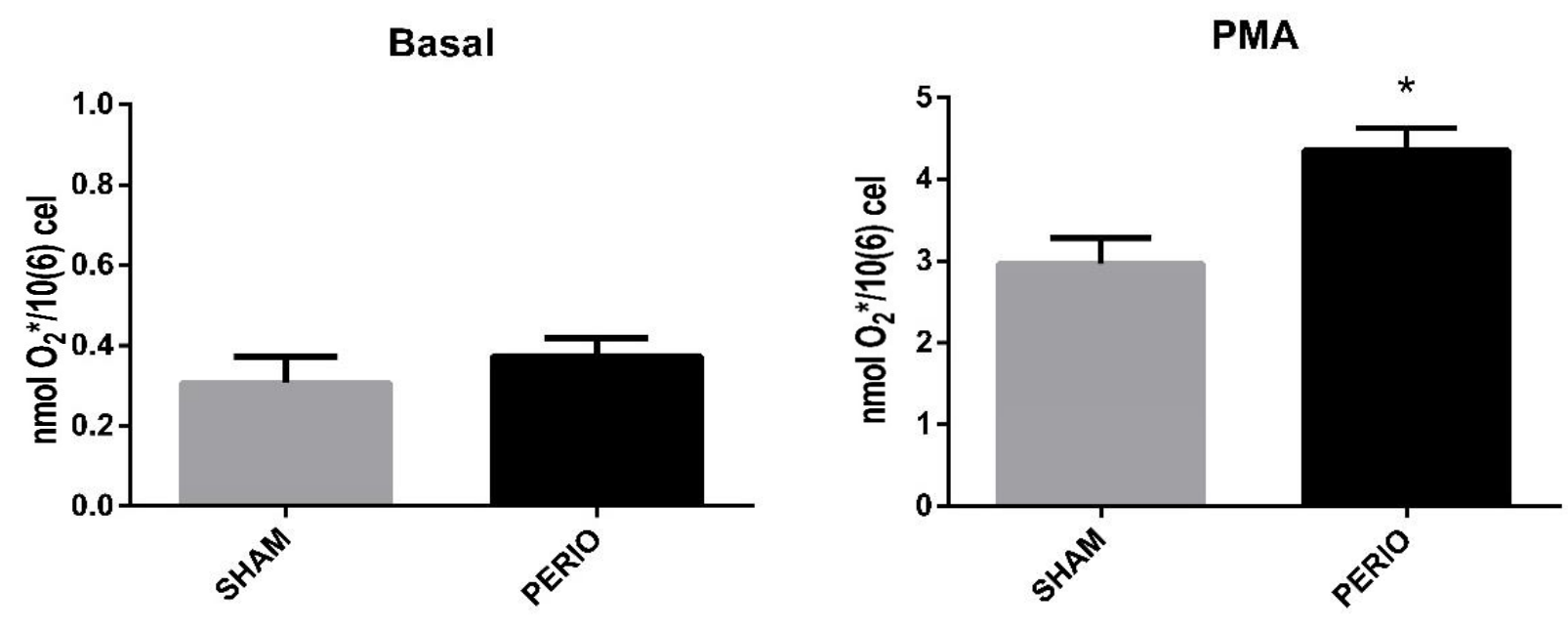

fMLP
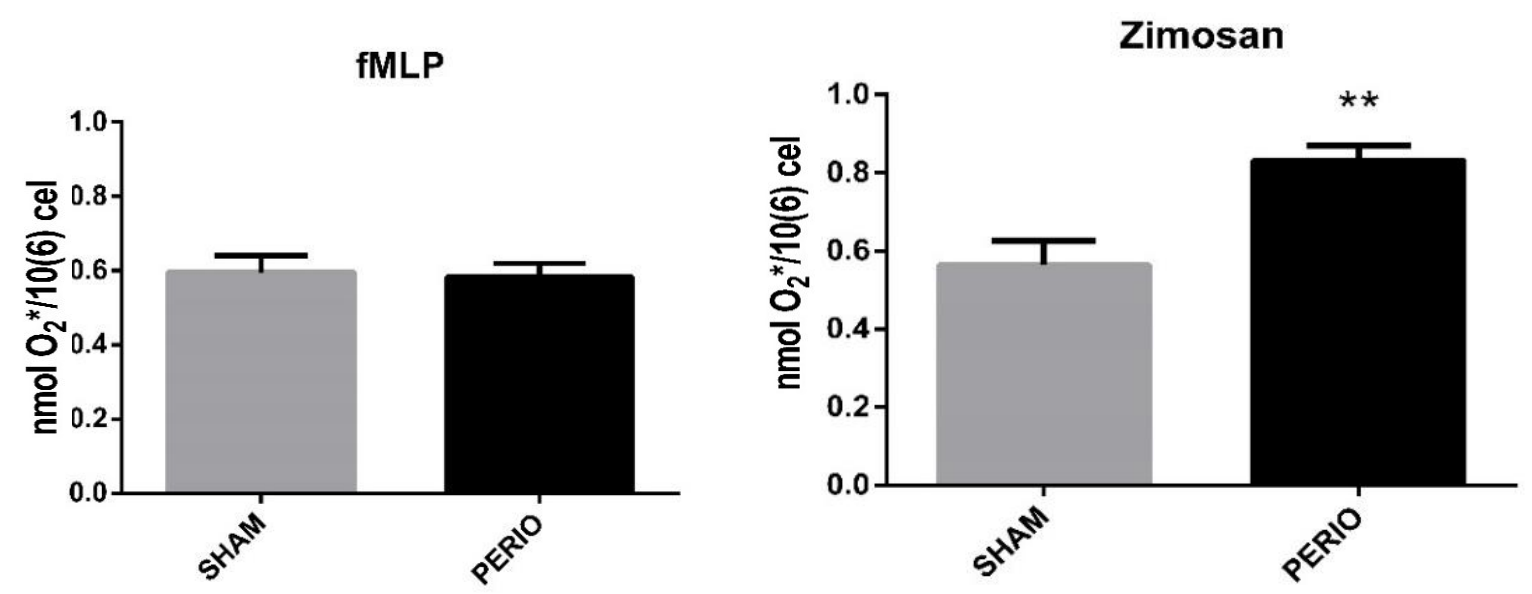

Efeito da ligadura em ratos na produção de ânion superóxido. Diferencia significativa na produção de ânion superóxido do grupo Perio quando estimulado com PMA $(P<0,05)$ e Zimosan $(P<0,01)$ em comparação com o grupo Sham, de acordo com o teste t de Student para dados não-pareados. No caso da produção Basal e quando estimulado com fMLP, não foram observadas diferenças significativas. 


\subsubsection{Liberação de mieloperoxidase.}

No grupo Sham, somente o fMLP promoveu aumento significativo da liberação de MPO (fMLP: $31,08 \pm 4,41$ vs. Basal: 18,54 $\pm 1,67 ; n=7 ; P<0,05$ ), e obtivemos diferenças

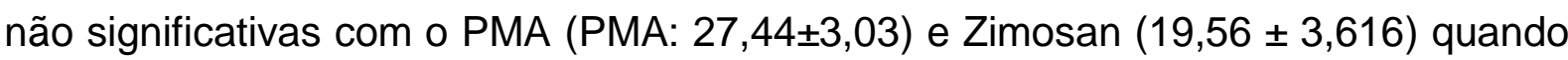
comparados com o Basal. No grupo Perio, somente o estímulo com PMA promoveu

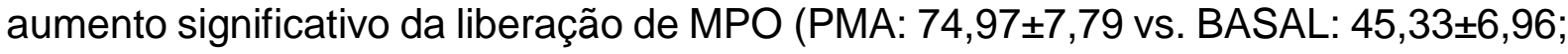
$P<0,05, n=5)$, enquanto nem o fMLP $(66,54 \pm 4,86 ; n=5)$ nem o Zimosan $(53,27 \pm$ $9,082 ; n=5)$ promoveram efeitos significativos. (Figura 11) 
Figura 11- Efeito da indução de periodontite sobre a atividade da mieloperoxidase pelos neutrófilos quando estimulados com PMA, fMLP e Zimosan. Comparação com a produção Basal nos grupos Sham e Perio.

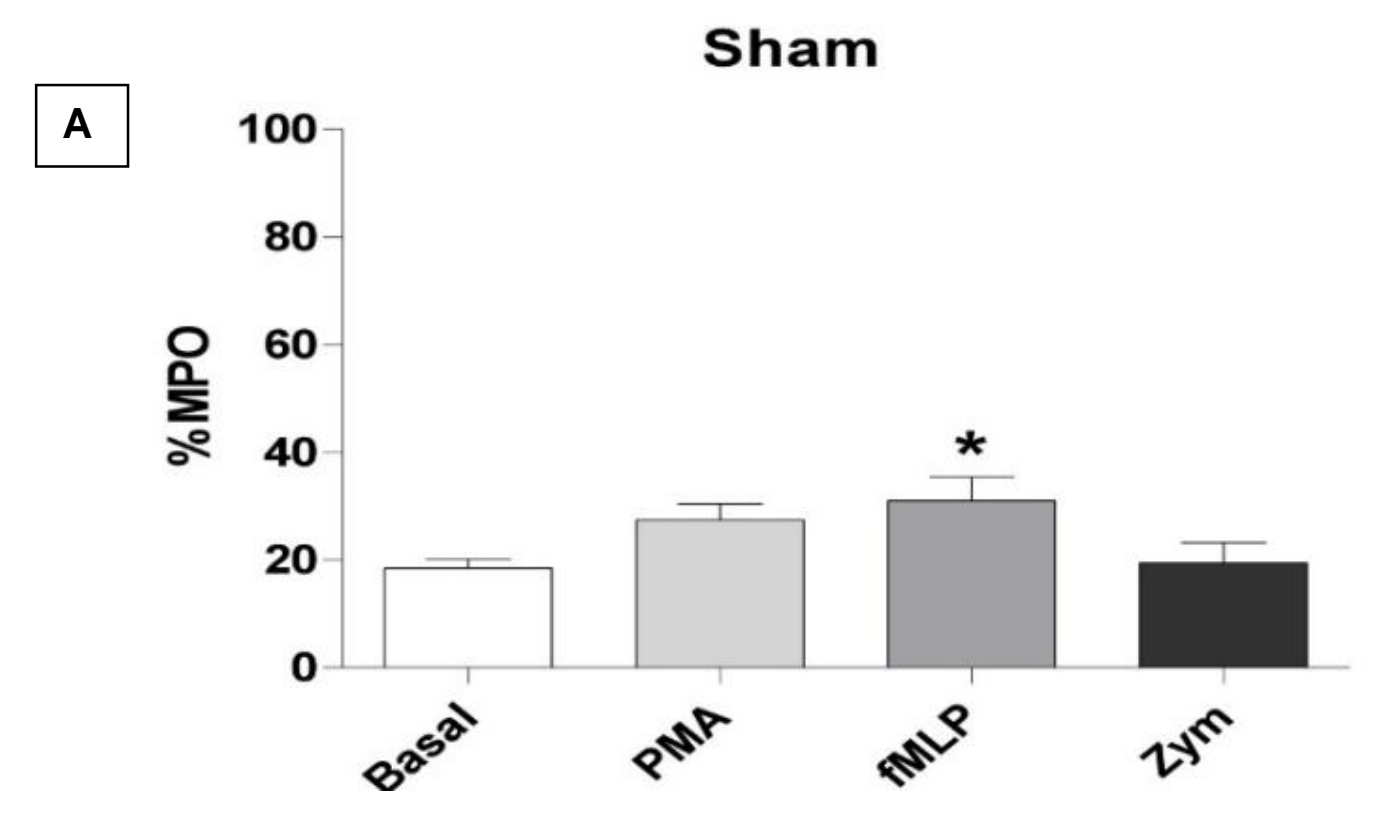

Perio

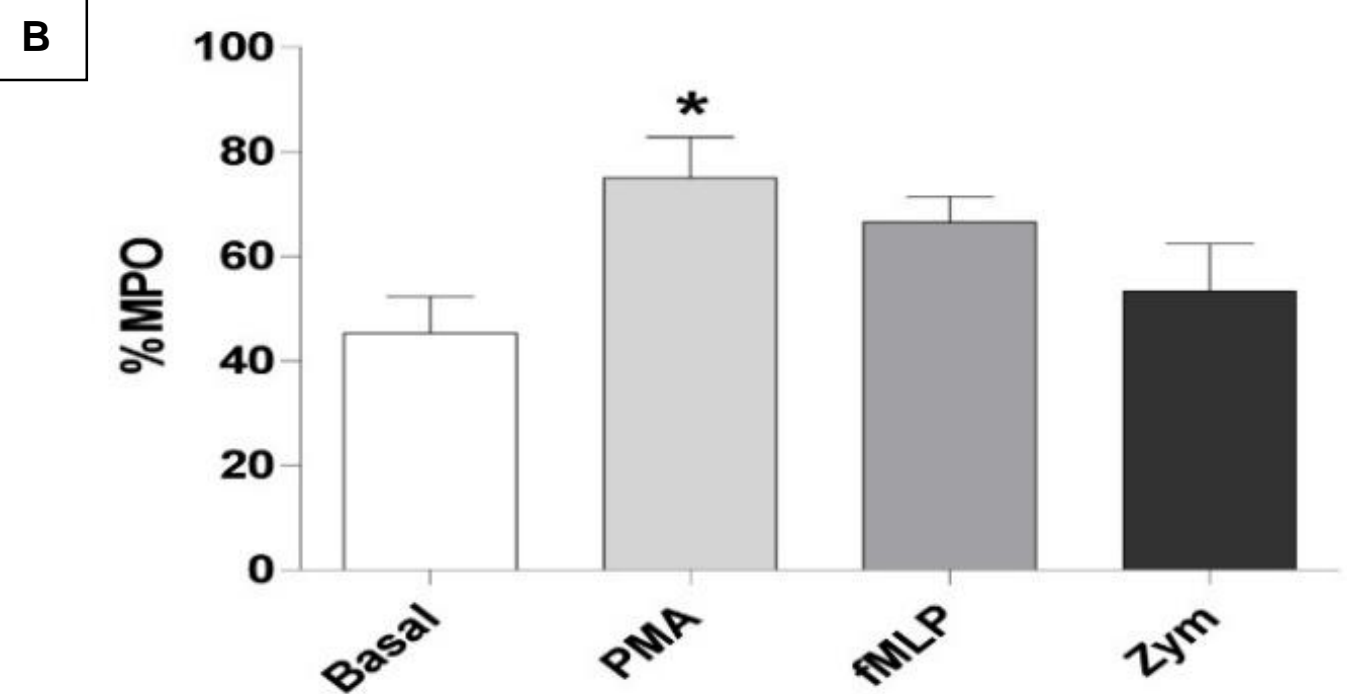

Efeito da ligadura em ratos na atividade da mieloperoxidase. Painel A: grupo Sham estimulado com PMA, fMLP $(P<0,05)$ e Zimosan quando comparado com o Basal. Painel B: grupo Perio estimulado com PMA $(P<0,05)$, fMLP e Zimosan quando comparado com o Basal, de acordo com o teste ANOVA de uma via seguido pelo teste de Dunnet. 
Comparando entre os grupos, observamos que a MPO liberada dos neutrófilos provenientes de animais do grupo Perio é estatisticamente maior daquela observada em animais do grupo Sham tanto em condições basais (Sham: 18,54 \pm 1,667, Perio: 45,33 $\pm 6,961, P<0,01$ ), como quando são estimulado com PMA (Sham: 27,44 $\pm 3,033$, Perio: 74,97 $\pm 7,785, P<0,001$ ), fMLP (Sham: $31,08 \pm 4,402$, Perio: $66,54 \pm 4,856$, $\mathrm{P}<0,01$ ) ou Zimosan (Sham: 19,56 $\pm 3,616$, Perio: $53,27 \pm 9,082, \mathrm{P}<0,01$ ) (Figura 12). 
Figura 12- Efeito da indução de periodontite sobre a atividade da mieloperoxidase dos neutrófilos no estado basal e quando estimulados com PMA, fMLP e Zimosan. Comparação entre os grupos Sham e Perio.

Basal

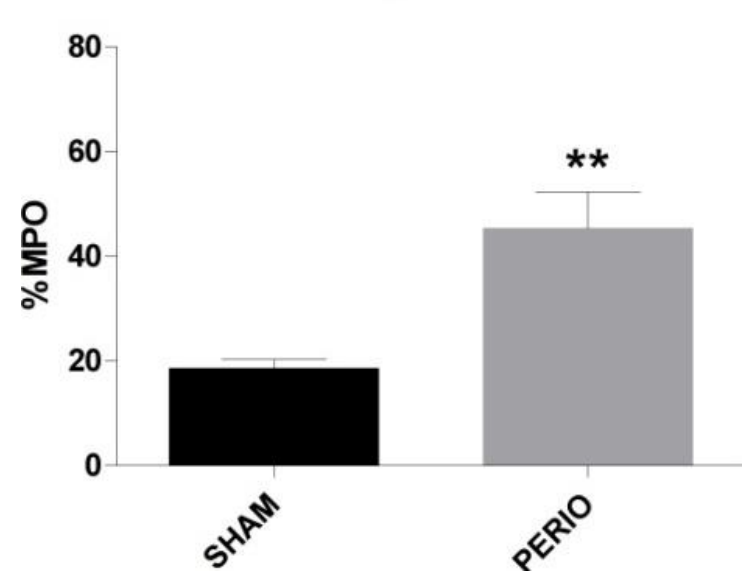

fMLP

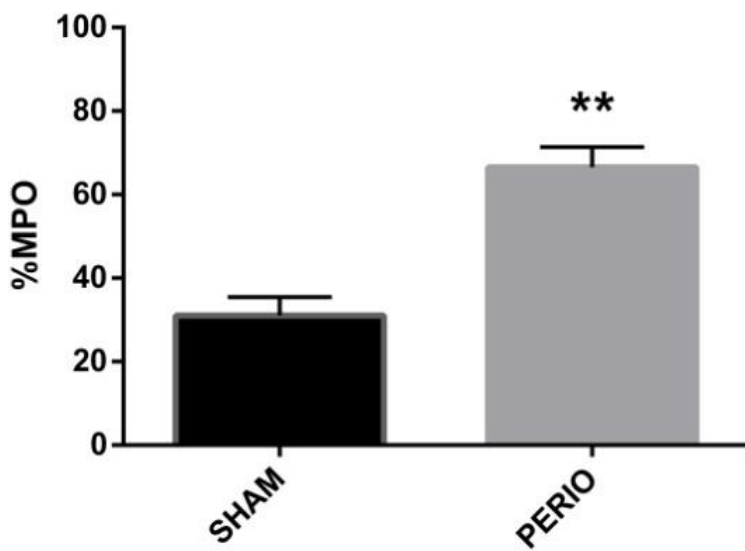

PMA

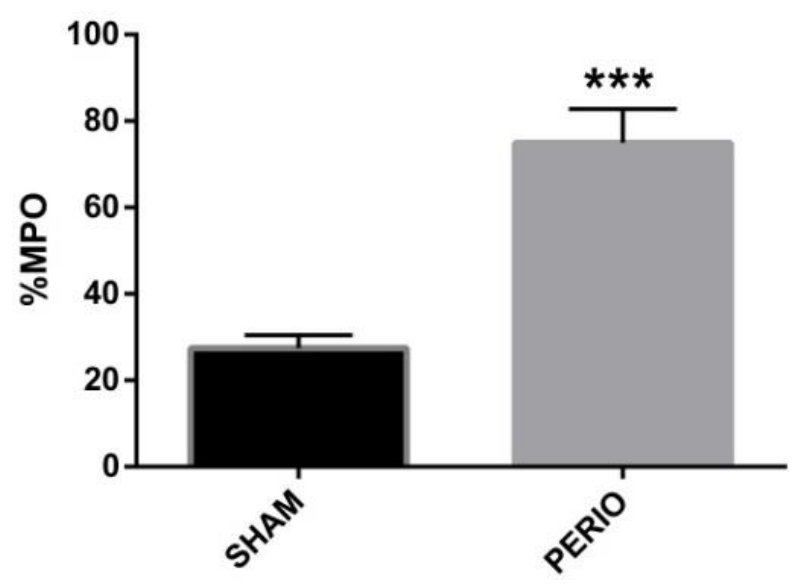

Zym

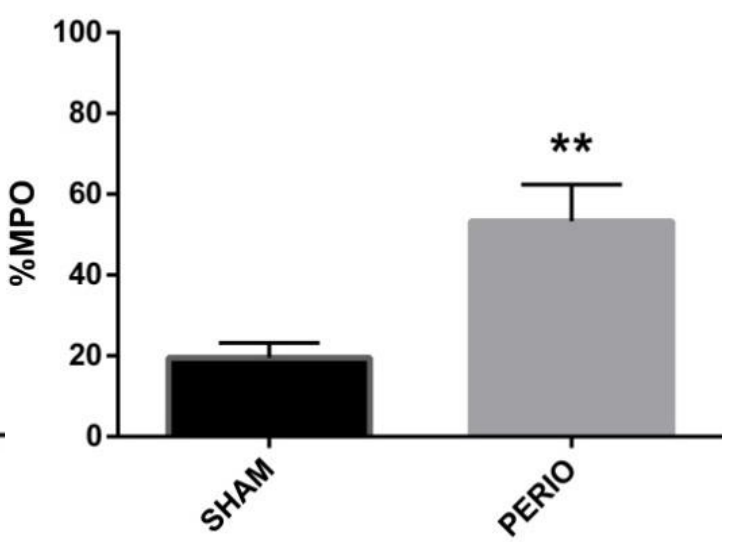

Efeito da ligadura em ratos na atividade da mieloperoxidase. Diferença significativa na atividade da mieloperoxidase do grupo Perio em estado Basal e quando estimulado com PMA, fMLP e Zimosan ( $n=5$ por grupo). ${ }^{\star \star} \mathrm{P}<0.01,{ }^{* \star *} \mathrm{P}<0.001$ significativamente diferente do grupo Sham, de acordo com o teste t de Student para dados não-pareados. 


\subsubsection{Formação de NETs}

Quando comparamos a formação de NETs no grupo Sham, os resultados mostram um aumento de atividade estatisticamente significativa quando estimulado com PMA (20772 $\pm 1721 ; n=7 ; P<0,05)$, fMLP $(19280 \pm 1044 ; n=7, P<0,05)$ e o Zimosan $(36021$ $\pm 4807 ; \mathrm{n}=6, \mathrm{P}<0,01)$ quando comparadas à atividade Basal $(15606 \pm 788 ; n=8)$. No grupo Perio, o estímulo com PMA (28393 $\pm 2470 ; n=9, P<0,01)$ e Zimosan (31229 \pm 3668; $n=9, P<0,01)$ são estatísticamente maiores; o fMLP $(22081 \pm 3274 ; n=5)$ não mostrou diferença significativa na atividade da MPO quando comparadas com a atividade Basal (19967 $\pm 1010, \mathrm{n}=9)$. Resultados expressos em unidades de fluorescência (UF). (Figura 13) 
Figura 13- Efeito da indução de periodontite sobre a produção de NETs pelos neutrófilos quando estimulados com PMA, fMLP e Zimosan. Comparação com a produção Basal.

\section{A}

\section{Sham}

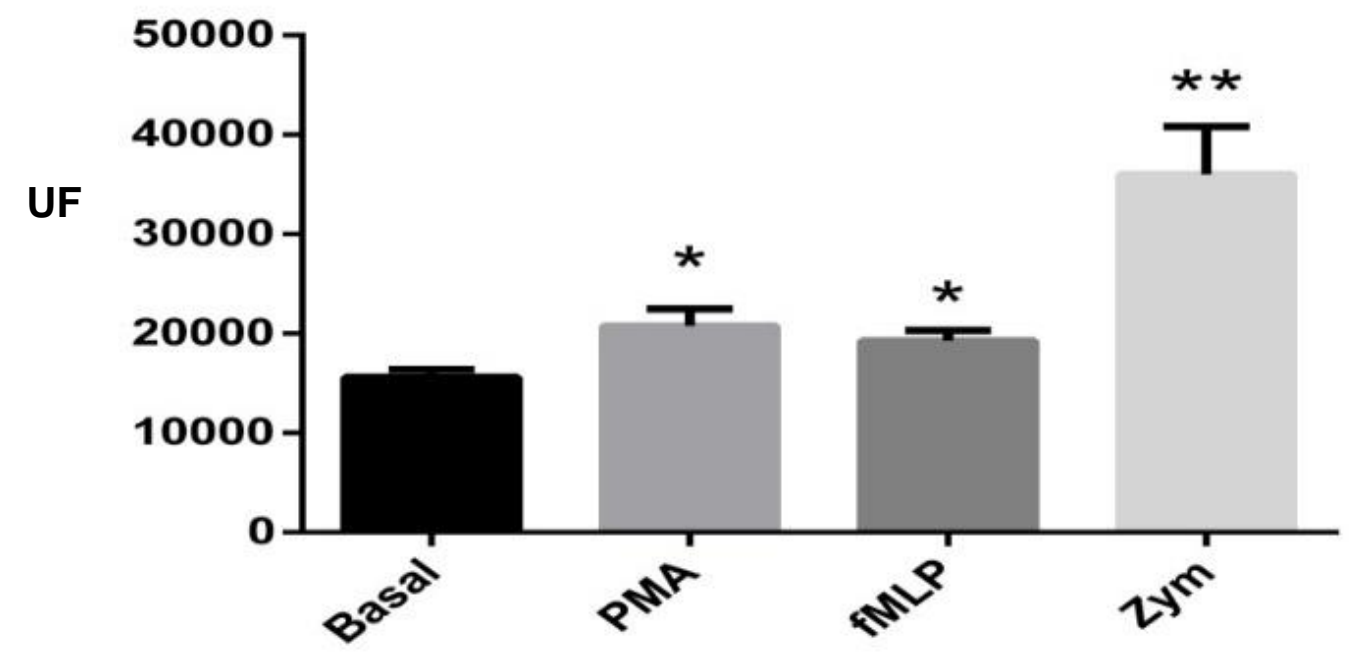

B

\section{Perio}

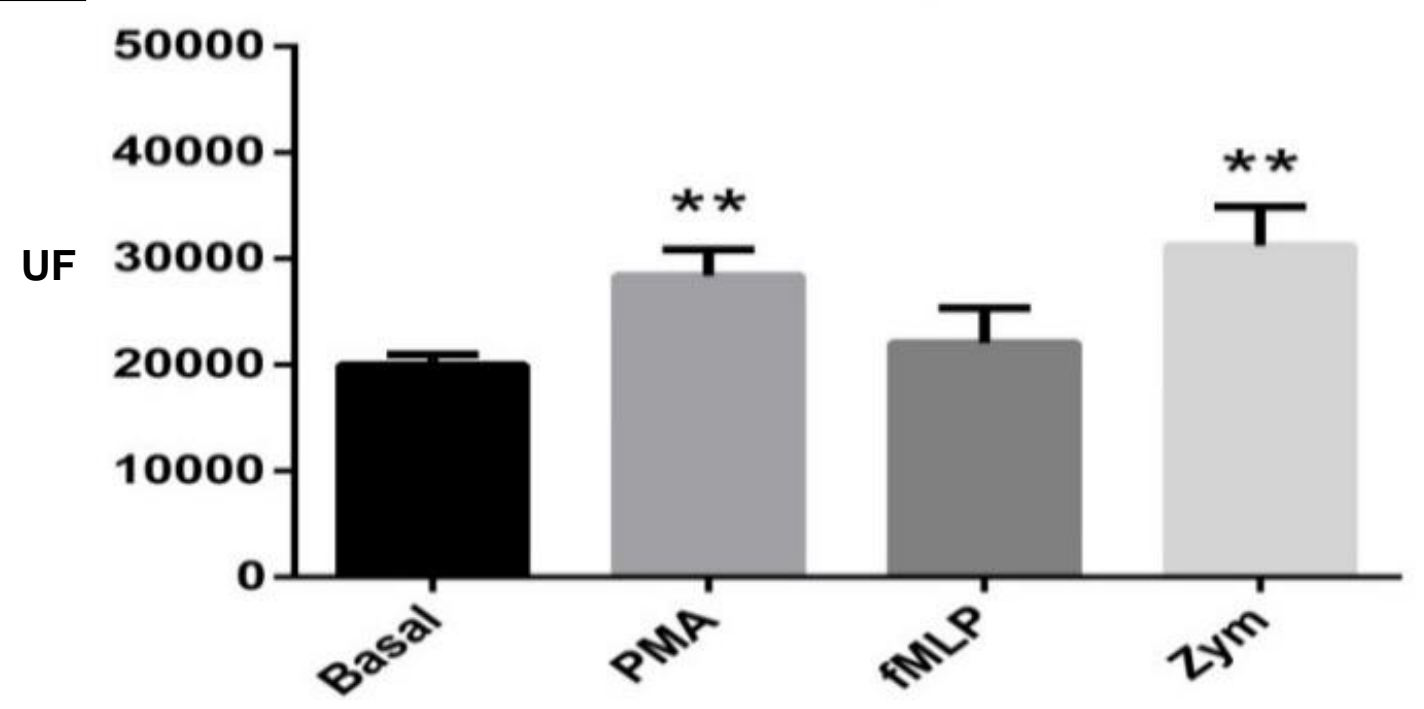

Efeito da ligadura em ratos na produção de NETs. Painel A: grupo Sham estimulado com $P M A(P<0,05)$, fMLP $(P<0,05)$ e Zimosan $(P<0,01)$ quando comparado com o Basal. Painel $B$ : grupo Perio estimulado com PMA $(P<0,05)$, fMLP e Zimosan $(P<0,01)$ quando comparado com o Basal, de acordo com o teste ANOVA de uma via seguido pelo teste de Dunnet. 
A produção das NETs dos neutrófilos provenientes de animais do grupo Perio é estatisticamente maior daquela observada em animais do grupo Sham tanto em condiciões basais $(P<0,01)$ como quando estimulado com PMA $(P<0,05)$, mas não foi observada diferencia significativa com os estímulos fMLP e Zimosan. (Figura 14). Resultados expressos em unidades de fluorescência (UF). 
Figura 14- Efeito da indução de periodontite sobre a formação das NETs dos neutrófilos no estado basal e quando estimulados com PMA, fMLP e Zimosan. Comparação entre os grupos Sham e Perio.
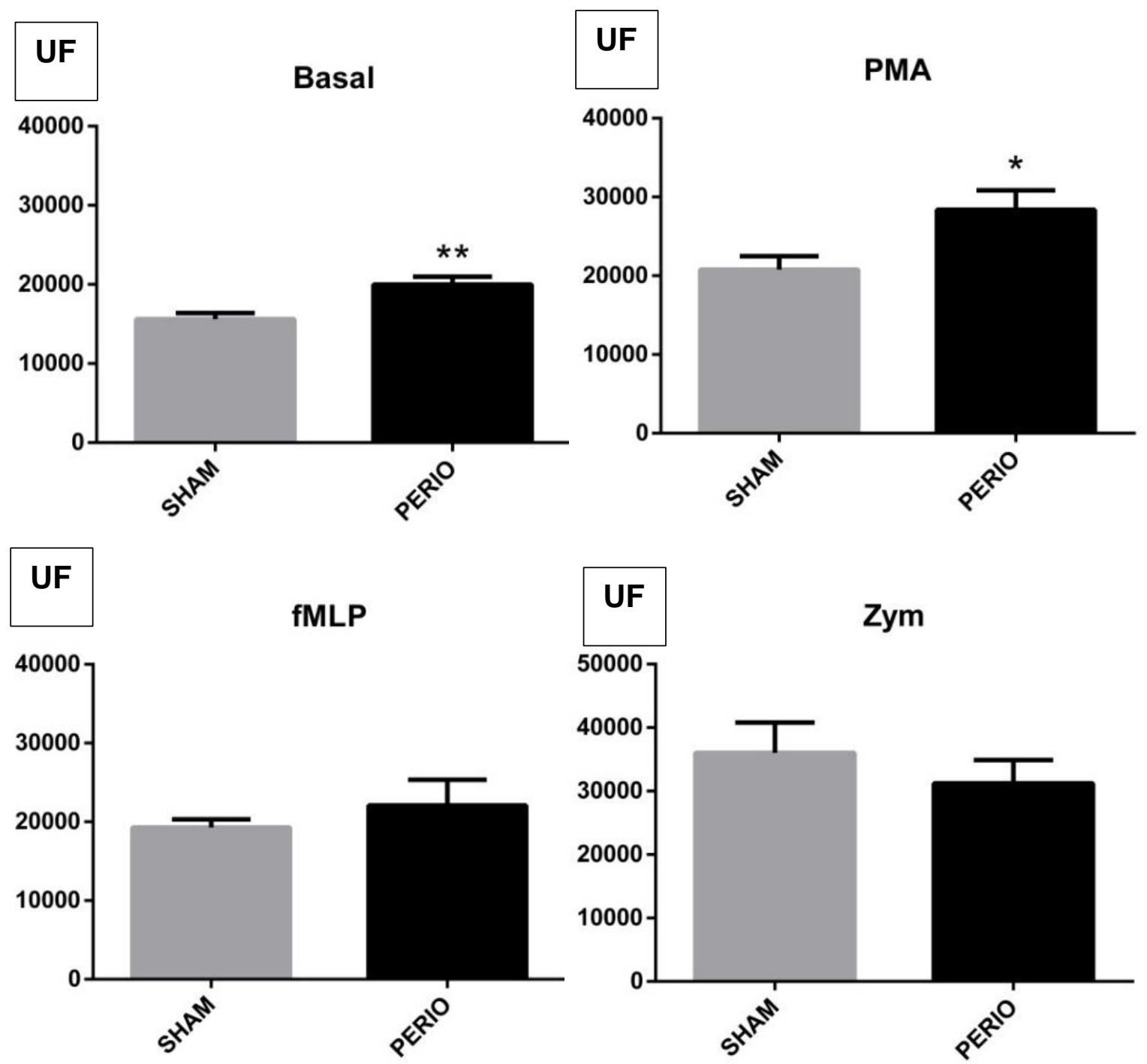

Efeito da ligadura em ratos na formação. Diferença significativa na atividade da mieloperoxidase do grupo Perio em estado Basal e quando estimulado com PMA, fMLP e Zimosan ( $n=5$ por grupo). ${ }^{*} \mathrm{P}<0.05$, ${ }^{* *} \mathrm{P}<0.01$ significativamente diferente do grupo Sham, de acordo com o teste t de Student para dados não-pareados. 


\section{DISCUSSÃO}

Normalmente, a periodontite é iniciada pela formação da placa e o bolso periodontal que é aproveitada por microrganismos com atividade patogénica até a resposta inflamatória aberrante do hospedeiro, que, no final, facilita a continuidade da infeção tornando a doença periodontal em um ciclo patogénico inflamatório. Neste trabalho foi demonstrado que a colocação de ligaduras nos primeiros molares inferiores promove aumento da perda óssea alveolar após 7 dias, característica do desenvolvimento da periodontite, fato que está de acordo com estudos prévios do nosso grupo de trabalho (Herrera et al., 2011) seguindo um modelo bem estabelecido de inflamação periodontal induzido por ligadura em roedores (Lohinai et al., 1998; Rovin et al., 1966) e que se baseia em facilitar o aumento localizado da placa bacteriana pela ligadura (Spolidorio et al., 2002). Também foi observado diminuição do ganho ponderal de peso no grupo de ratos com ligadura avaliados no sétimo dia. Tanto o grupo Sham como o Perio tiveram a média do peso inicial semelhantes, confirmando que a diferença de ganho ponderal entre os grupos está relacionada à presença das ligaduras em torno dos primeiros molares inferiores, provavelmente por dificultar a ingestão da ração, mesmo com uma dieta normal ad libitum, embora algumas pesquisas indiquem a necessidade de uma ingestão calórica normal para o desenvolvimento do processo inflamatório (Branch-Mays et al., 2008).

Os leucócitos polimorfonucleares neutrofílicos (neutrófilos) são as células predominantes na resposta imuno-inflamatória, sendo fundamental na retirada das bactérias. No entanto, em pacientes susceptíveis por fatores genéticos, de saúde ou ambientais, os neutrófilos se tornam disfuncionais e falham na eliminação da bactéria patogênica o que desenvolve uma discordância entre a resposta do hospedeiro e o biofilme (Scott, Krauss, 2012). Além disso, existem outras consequências para a saúde já que esta situação contribui para o aumento da carga inflamatória sistémica, o qual é associado ao aumento no risco com condições relacionadas à idade, como a artrite reumatoide (Smit et al., 2012). De fato, neutrófilos circulantes de pacientes com periodontite crónica são hiper-reativos com relação à liberação de ROS em resposta a um desafio microbiano e também hiperativo em ausência de um estímulo exógeno ( $P$. gingivalis e F. nucleatum) (Cooper et al., 2007; Ling-Mountford et al., 2007). Por tanto, parece-nos interessante avaliar a resposta dos neutrófilos periféricos em um 
modelo experimental com periodontite decorrente, que no nosso caso foi induzida por ligadura em ratos.

Uma primeira análise realizada foi avaliar como a periodontite afeta na quantidade de neutrófilos circulantes totais. A liberação de neutrófilos desde a medula óssea aumenta durante períodos de infeção em resposta à demanda do sistema imune (Metcalf, 1991) para depois procurar microrganismos invasores. Eles têm um tempo de vida na circulação de aproximadamente 5 dias nos humanos e até um dia em ratos (Kolaczkowska et al., 2013), mas este tempo pode aumentar se eles são primados por ação de componentes bacterianos (p.e. endotoxinas) ou por mediadores do hospedeiro (p.e. complementos e/ou várias citocinas). Após serem primados, eles extravasam para entrar nos tecidos infectados e subsequentemente transitar por este tecido na quimiotaxia, que pode ser orquestrada por CXCL8, componentes do complemento e peptídeos bacterianos (fMLP). Nos processos inflamatórios, a precisão da migração quimiotáctica dos neutrófilos está afetada, o que aumenta o tempo dos neutrófilos nos tecidos (Roberts et al., 2015). Neste ponto, nossos resultados evidenciaram um aumento de quase $50 \%$ dos neutrófilos circulantes, os quais também tem características de hiperreatividade e hiperatividade, o que facilitaria a atividade citotóxica dos neutrófilos circulantes em tecidos não infetados. Também observamos uma diminuição porcentual dos linfócitos em uma quantidade que compensava o aumento de neutrófilos, possivelmente mantendo a quantidade de linfócitos em sangue e também por um possível aumento no número das outras células brancas (p.e. monócitos) já que estes mantem sua porcentagem em ambos grupos experimentais (apróx. 5\%) mesmo com um aumento no total de leucócitos por causa dos neutrófilos. Alguns estudos indicam que, no humano, os linfócitos têm uma contagem aumentada no sangue apenas nos casos de periodontite severa, já que neste ponto a cronicidade e severidade iniciou uma resposta do sistema imune adaptativo (Loos et al., 2004).

A fim de alcançar o objetivo de eliminar patógenos periodontais invasores, os neutrófilos têm um substancial arsenal antimicrobiano: fagocitose, produção de ROS, degranulação intracelular e extracelular (Jaillon et al., 2013). Entretanto, e como mencionado anteriormente, em 2004 foi reportado um novo mecanismo mediado pelos neutrófilos: as neutrophil extracellular traps (NETs) (Brinkmann et al. 2004). Sua estrutura tipo rede de cromatina nuclear descondensada e associada a uma variedade de compostos antimicrobianos, incluindo histonas e peptídeos antimicrobianos (AMP) 
de azurófilos, específicos e grânulos de gelatinase, abrange as principais vias de ação dos neutrófilos, pelo qual nossa análise será focado nesta resposta que ainda envolve a morte do neutrófilo. A liberação do conteúdo neutrofílico pode produzir autoantígenos, situação estudada recentemente pela conexão entre periodontite e outras doenças inflamatórias crónicas, como mencionado anteriormente.

A extrusão do DNA requere apropriada transdução de sinal de múltiplos receptores (p.e. receptores do tipo Toll, receptores de citocinas e receptor Fc gama). Como mencionado anteriormente, um dos primeiros passos essenciais para a produção das NETs, além de qualquer outra resposta do neutrófilo, é a produção de ânion superóxido. As análises feitas neste trabalho mostram que os 3 estímulos utilizados (um ativador da PKC, um ativador do receptor de peptídeos $\mathrm{N}$-formilados e uma partícula fagocitável) aumentam a produção do superóxido em relação à resposta não estimulada (basal), seja no grupo com ratos sadios ou no grupo de ratos com periodontite. Este resultado era o esperado, já que a produção de superóxido é necessária para as respostas mais básicas (fornecimento de substrato para a MPO dos fagossomos) e até para as mais complexas, como a produção das NETs. Comparando as respostas de ambos os grupos (periodontite e Sham) não foi achada diferença entre os grupos experimentais nas condições basais, porém, observamos que existe um aumento marcado quando os neutrófilos são estimulados pelo PMA ou Zimosan. Como mostrado na Figura 2, o PMA ativa diretamente a proteína kinase C, pelo que o resultado é o esperado. Por outra parte, o Zimosan induz a ativação dos fagossomos para sua respectiva fagocitose, o que produz um aumento do peróxido necessário para os fagossomos ativos e formar outros ROS, preparando a resposta do neutrófilo. Já no caso do fMLP, estímulo que não aumentou a produção de superóxido no grupo periodontite, sua principal ação no neutrófilo é a de recrutamento, aumentando a quimiotaxia, com uma resposta fraca na geração de superóxido, porém importante para outras vias.

As análises da atividade da MPO foram feitas comparando a relação entre a atividade da MPO total da amostra e a atividade da MPO liberada dos grânulos ou com as NETs. Desta maneira avaliamos intensidade da resposta relacionando a liberação de MPO ao total para evitar variabilidade devida ao conteúdo pré-existente entre os animais. Foi encontrado que, fazendo comparações dentro de cada grupo experimental, apenas o Zimosan no grupo Sham e o PMA no grupo periodontite tiveram aumentos significativos, mesmo tendo todos os estímulos médias maiores do 
que o grupo basal. Mas analisando se o grupo com periodontite tem maior atividade do que o grupo Sham, foi achado que todos os estímulos aumentaram esta atividade. O MPO é uma enzima que precisa de substratos que são na sua vez produtos de outras enzimas, por exemplo da NADPH oxidase. Isso possivelmente explica por que os estímulos que apresentam aumento significativo neste parâmetro não o tiveram na análise da produção de ânion superóxido que seria um substrato prévio para a geração de $\mathrm{HClO}$, como representado na Figura 1. Mais uma vez, os 3 estímulos coincidem na ativação de vias necessárias para a resposta do neutrófilo fazendo uso dos seus grânulos azurófilos, lugar onde a MPO é estocada. Além disso, foi encontrado que os neutrófilos dos ratos com periodontite têm uma atividade relativa de MPO aumentada em comparação com o grupo Sham. Estes resultados são muito importantes, já que demonstram a hiperatividade dos neutrófilos circulantes periféricos devido à inflamação do periodonto.

A liberação de NETs está governada pela magnitude e cronicidade do estímulo. Vários estudos utilizam o PMA por 4h com estímulos (Brinkmann, Zychlinsky, 2007), mas também tem sido reportado que o estimulo $\mathrm{HClO}$ induz a produção de NETs, fazendo um by-pass que evita a ativação da NADPH oxidase com resultados em apenas 1 hora (Cooper et al., 2012). Neste trabalho observamos aumento da geração de NETs incubando as células por $1 \mathrm{~h}$ para cada estimulo (em relação à atividade basal). Quando estimulado com PMA, se espera uma resposta intensa do neutrófilo devido à grande quantidade de superóxido produzido e também pela importância deste para a produção das NETs, informação que coincide com nossos resultados. Também evidenciamos hiperreatividade ao estimular os neutrófilos com PMA, já que existe um maior aumento da produção de NETs no grupo com periodontite do que o aumento observado no grupo Sham. Interessantemente, observamos também que existe uma hiperatividade dos neutrófilos das amostras com periodontite, mesmo na ausência de estímulos exógenos que ativem vias importantes como já foi dito anteriormente. Nossos resultados mostram apenas aumento da liberação de MPO, mas não da produção de ânion superóxido nas células não estimuladas. Pilsczek et al. (2010) observaram a produção de NETs independente de espécies reativas de oxigênio usando Staphylococcus aureus como estímulos por apenas 10 minutos. Este mecanismo rápido envolve expulsão de vesículas secretoras intactas, o que fez aos autores supor que a liberação de NETs é dependente da exocitose vesicular mais do que da ativação de NADPH oxidase, mesmo usando inibidores dessa enzima (cloreto 
de difeniliondônio - DPI). No entanto, também existem estudos realizados com pacientes com doença granulomatosa crónica (os quais apresentam mutações nas subunidades do complexo NADPH oxidase e não produzem ânion superóxido) os quais são incapazes de produzir NETs (Fuchs et al., 2007).

Em pacientes com periodontite crónica foi relatada a existência de uma outra via de ativação indireta envolvendo as plaquetas que se ligam e ativam neutrófilos via TLR4 (Clark et al., 2007), sendo que estes pacientes apresentam contagem elevada destes componentes sanguíneos. Por outro lado, compostos mediadores do sistema imune (tais como AMP LL37, IL-8 e MIP1- $\alpha$ ) com capacidade para recrutar e primar ou ativar neutrófilos podem ter a sua transcrição gênica de novo nos neutrófilos uma vez fora da medula óssea (Neumann et al., 2014), além de outros componentes, tais como as citocinas proinflamatórias TNF- $\alpha$ e IL-1 $\beta$ (Keshari et al., 2012). A fim de melhor entender as vias que fazem possível a produção de NETs apenas por influência da inflamação local do periodonto, em experimentos futuros quantificaremos e compararemos estes componentes no nosso modelo de periodontite.

Em contraste aos benefícios propostos das NETs, excesso da sua formação tem sido associada a doenças autoimunes severas. Apesar de que a remoção das NETs seja um evento grandemente orquestrado desenhado para não ativar uma resposta imune, excessos da liberação das NETs ou remoção demorada pode prover uma fonte de autoantígenos em doenças autoimunes e contribuir no dano ao tecido. A hiperreatividade e, de modo mais importante, a hiperatividade dos neutrófilos do sangue periférico não diretamente envolvidos na inflamação local do periodonto demonstrada neste trabalho evidência a possibilidade de que tecidos saudáveis possam ser afetados por produtos da atividade neutrofílica citotóxicos ou que sejam alvos de respostas autoimunes. Por exemplo, se sabe que anticorpos citoplasmáticos antineutrófilos estão presentes em $50 \%$ dos pacientes com lúpus eritematoso sistémico (Fauzi et al., 2004). Também, em pacientes susceptíveis a sofrer esta doença, têm sido achados autoanticorpos para várias proteínas granulares do neutrófilo, tais como a MPO e o PR3, além de ter quase impedida a remoção de NETs liberadas (Hakkim et al., 2010). A remoção demorada de NETs também fornece um reservatório de proteínas hipercitrulinadas dentro do espaço extracelular, o que pode elevar o título de anticorpos anti-dsDNA e por tanto contribuir para a sua patogenicidade (Knight et al., 2012). Os anticorpos anti-proteína citrulinada (ACPAs) são indicadores específicos de diagnóstico na artrite reumatoide e as NETs são ricas em peptídeos citrulinados. 
De fato, ACPAs reage com histonas encontradas em NETs, indicando que as NETs podem ser imunogênicas e desencadear um ciclo vicioso caracterizado pela ligação da ACPAs às NETs dentro das articulações com a consequente ligação ao receptor Fcy neutrofílico e a posterior liberação de NETs. Este fenómeno é associado ao aumento da severidade da doença (Pratesi et al., 2014). Pesquisas recentes apontam uma possível associação entre artrite reumatoide e a bactéria periodontogênica Porphyromonas gingivalis, A qual expressa uma enzima PAD única que funciona de forma análoga à isoforma expressa em mamíferos (Koziel et al., 2014), podendo a isoforma bacteriana citrulinar proteínas da bactéria (uma forma de mimetismo molecular), ou do hospedeiro e, por tanto, gerar ACPAs. 


\section{$6 \quad$ CONCLUSÕES}

Com base nos resultados mostrados, podemos concluir que:

$\checkmark \quad$ A inflamação do tecido periodontal induzida por ligadura em ratos induz aumento na proporção de neutrófilos circulantes.

$\mathrm{Na}$ presença de periodontite, os neutrófilos circulantes apresentam tanto hiperatividade (na ausência de estímulos externos) como hiperreatividade, avaliadas como produção de ânion superóxido, liberação de mieloperoxidase e formação de NETs, quando estimulados pela ativação da PKC, ativação do receptor de peptídeos $\mathrm{N}$-formilados e ativação do processo fagocítico.

$\checkmark \quad$ Atividade neutrofílica exacerbada pode explicar o nexo agravante e de cronicidade da periodontite concomitante com outras doenças inflamatórias. 


\section{REFERÊNCIAS*}

Almeida RP, Vanet A, Witko-Sarsat V, Melchior M, McCabe D, Gabay JE. Azurocidin, a natural antibiotic from human neutrophils: expression, antimicrobial activity, and secretion. Protein Expr Purif. 1996.

Andersen E, Cimasoni GA. Rapid and simple method for counting crevicular polymorphonuclear leucocytes. J Clin Periodontol. 1993;20(9):651-5.

Athens JW, Haab OP, Raab SO et al. Leukokinetic studies. IV. The total blood, circulating and marginal granulocyte pools and the granulocyte turnover rate in normal subjects. J Clin Invest. 1961;40:989-95.

Babior BM, Kipnes RS, Curnutte JT. Biological defense mechanisms: production by leukocytes of superoxide, a potential bactericidal agent. J Clin Invest. 1973;52:741-4.

Babior, B., M. NADPH oxidase: an update. Blood. 1999;93:1464-76.

Bainton DF, Farquhar MG. Differences in enzyme content of azurophil and specifi C granules of polymorphonuclear leukocytes. J Cell Biol. 1968;39:286-98.

Bainton DF, Ullyot JL, Farquhar MG. The development of neutrophilic polymor phonuclear leukocytes in human bone marrow. J Exp Med. 1971;134:907-34.

Bender JS, Thang $\mathrm{H}$, Glogauer $\mathrm{M}$. Novel rinse assay for the quantification of oral neutrophils and the monitoring of chronic periodontal disease. J Periodontal Res. 2006;41(3):214-20.

Berg JT. Zymosan Priming Protects Rats Against Pulmonary Oxygen Toxicity: Characterization Of The Model. Exp. Biol. Med. 2010;235:170-4.

Borregaard N, Cowland JB. Granules of the human neutrophilic polymorphonuclear leukocyte. Blood. 1997;89:3503-21.

Borregaard N, Sorensen OE. Theilgaard-Monch K. Neutrophil granules: a library of innate immunity proteins. Trends Immunol. 2007;28(8):340-5.

Borregaard N. Development of neutrophil granule diversity. Ann N Y Acad Sci. 1997;832:62-8.

Bosshardt DD, Schroeder HE. Cementogenesis reviewed: a comparison between human premolars and roden molars. Anat Rec. 1996;245(2):267-92.

\footnotetext{
*De acordo com:

International Committee of Medical Journal Editors. [Internet]. Uniform requirements for manuscripts submitted to biomedical journals. [2011 Jul 15]. Available from:

http://www.nlm.nih.gov/bsd/uniform_requirements.html.
} 
Bradley et al. Measurament of cutaneous inflammation: Estimation of neutrophil content with an enzyme marker. J Invest Dermatol. 1982;78:206-9.

Branch-Mays GL, Dawson DR, GunsolleyJC, Reynold MA, Ebersole JL, Novak KF, Mattison JA, Ingram DK, Novak MJ. The effects of a calorie-reduced diet on periodontal inflammation and disease in a non-human primate model. J Periodontol. 2008; 79(7): 1184-91.

Brumell JH, Volchuk A, Sengelov H, Borregaard N, Cieutat AM, Bainton DF, Grinstein $\mathrm{S}$, Klip A. Subcellular distribution of docking/fusion proteins in neutrophils, secretory cells with multiple exocytic compartments. J Immunol. 1995;155(12):5750-9.

Campi P, Herrera BS, De Jesus FN, Napolitano M, Teixeira SA, Maia-Dantas A, et al. Endothelial dysfunction in rats with ligature-induced periodontitis: Participation of nitric oxide and cycloxygenase-2-derived products. Arch Oral Biol. 2016;63:66-74.

Chapple IL, Genco R. Diabetes and periodontal diseases: consensus report of the Joint EFP/AAP Workshop on Periodontitis and Systemic Diseases. Journal of clinical periodontology. 2013;40.

Chow OA, von Köckritz-Blickwede M, Bright AT, Hensler ME, Zinkernagel AS, Cogen $A L$, et al. Statins enhance formation of phagocyte extracellular traps. Cell Host Microbe 2010;8(5):445-54.

Chung WO, Dommisch H, Yin L. Dale BA. Expression of defensins in gingiva and their role in periodontal health and disease. Curr Pharm Des. 2007;13(30):3073-83.

Clark RA. The human neutrophil respiratory burst oxidase. J Infect Dis. 1990;161:1140-7.

Condino-Neto A. Neutrophils and mononuclear cells from patients with chronic granulomatous disease release nitric oxide. Br J Clin Pharmacol. 1993;35: 485-490.

Cowburn AS, Condliffe AM, Farahi N, Summers C, Chilvers ER. Advances in neutrophil biology: clinical implications. Chest. 2008;134(3):606-12.

Deas D, Mackey E, McDonnell SA. Systemic disease and periodontitis: manifestations of neutrophil dysfunction. Periodontol 2000. 2003;32:82-104.

DiStasi MR, Ley K. Opening the flood-gates: how neutrophil-endothelial interactions regulate permeability. Trends Immunol. 2009;30(11):547-56.

Dypbukt J. A sensitive and selective assay for chloramine production by myeloperoxidase. Free Radic Biol. 2005.

Franco-Penteado CF, De Souza IA, Camargo EA, Teixeira AS, Muscara MN, De Nucci $G$, Antunes E. Mechanisms involved in the enhancement of allergic airways neutrophil 
influx by permanent C-fiber degeneration in rats. $J$ Pharmacol Exp Ther. 2005;313(1):440-8.

Fuchs TA, Abed U, Goosmann C, Hurwitz R, Schulze I, Wahn V, Weinrauch Y, Brinkmann V, Zychlinsky A. Novel cell death program leads to neutrophil extracellular traps. The Journal of cell biology. 2007;176:231-41.

Gonzalez AS. Induction and Quantification of Neutrophil Extracellular Traps. In: Quinn, M., T. DeLeo, F., R. editors. Neutrophil Methods and Protocols. Local: Humana Press. 2014. p. 307-18.

Guzik K, Skret J, Smagur J, Bzowska M, Gajkowska B, Scott DA. Potempa JS. Cigarette smoke-exposed neutrophils die unconventionally but are rapidly phagocytosed by macrophages. Cell Death Dis. 2011.

Hajishengallis G. Immunomicrobial pathogenesis of periodontitis: keystones, pathobionts, and host response. Trends in immunology. 2014;35:3-11.

Hayashi F, Means TK, Luster AD. Toll-like receptors stimulate human neutrophil function. Blood. 2003;102(7):2660-9.

Herrera BS, Martins-Porto R, Campi $P$, et al. Local and cardiorenal effects of periodontitis in nitric oxide-deficient hypertensive rats. Archives of Oral Biology. $2011 ; 56(1): 41-7$.

Hoebe K, Janssen E, Beutler B. The interface between innate and adaptive immunity. Nat Immunol. 2004;5:971-4.

Iwata T, Yamato M, Ishikawa I, Ando T, Okano T. Tissue engineering in periodontal tissue. Anat Rec (Hoboken). 2014; 297(1): 16-25.

Johnson JL. Disparities in the respiratory burst between human and rat neutrophils. $J$ Leukoc Biol. 1999;65(2):211-6.

Kennedy AD, DeLeo FR. Neutrophil apoptosis and the resolution of infection. Immunol Res. 2009;43(1-3):25-61.

Klebanoff SJ. Iodination of bacteria: a bactericidal mechanism. J Exp Med. 1967;126:1063-78.

Lakschevitz FS, Visser MB, Sun C, Glogauer M. Neutrophil transcriptional profile changes during transit from bone marrow to sites of inflammation. Cell Mol Immunol 2015; 12: 53-65.

Le Cabec V, Cowland JB, Calafat J, Borregaard N. Targeting of proteins to granule subsets is determined by timing and not by sorting: The specific granule protein NGAL is localized to azurophil granules when expressed in HL-60 cells. Proc Natl Acad Sci U S A. 1996;93(13):6454- 7. 
Lehrer RI, Hanifin J, Cline MJ. Defective bactericidal activity in myeloperoxidase deficient human neutrophils. Nature. 1969;223:78-9

$\mathrm{Li}$ Y, Ye D. Molecular biology for formyl peptide receptors in human diseases. Journal of Molecular Medicine.2013; 91(7):781-9.

Liu RK, Cao CF, Meng HX, Gao Y. Polymorphonuclear neutrophils and their mediators in gingival tissues from generalized aggressive periodontitis. J Periodontol. 2001; 72(11):1545-53.

Matthews JB. Hyperactivity and reactivity of peripheral blood neutrophils in chronic periodontitis. Clin Exp Immunol. 2007;147: 255-64 .

Meng $\mathrm{H}$. Determinants of host susceptibility in aggressive periodontitis. Periodontol 2000. 2007;43:133-59.

Nauseef WM, Clark RA. Granulocytic phagocytes. In: Mandell, G., L. Bennett, J., P. Dolin, R. (eds) Basic principles in the diagnosis and management of infectious diseases. 5th edn. Churchill Livingstone. 2000. pp 89-112.

Nesse W. The periodontium of periodontitis patients contains citrullinated proteins which may play a role in ACPA (anti-citrullinated protein antibody) formation. J Clin Periodontol. 2012;39:599-607.

Palmer L, Cooper P, Ling M, Wright H, Huissoon A, Chapple I. Hypochlorous acid regulates neutrophil extracellular trap release in humans. Clinical \& Experimental Immunology. 2012;167(2):261-8.

Pham CT. Neutrophil serine proteases fine-tune the inflammatory response. Int J Biochem Cell Biol. 2008;40(6-7):1317-33.

Reeves EP, Lu H, Jacobs HL, Messina CG, Bolsover S, Gabella G, Potma EO, Warley A, Roes J, Segal AW. Killing activity of neutrophils is mediated through activation of proteases by K+ flux. Nature. 2002;416(6878):291-7.

Ryder MI. Comparison of neutrophil functions in aggressive and chronic periodontitis. Periodontol 2000. 2010;53:124-37.

Sallay K. Alveolar bone destruction in the immuno-suppressed rat. J Periodontal Res. 1982;17:263-74.

Schenkein HA. Host responses in maintaining periodontal health and determining periodontal disease. Periodontol 2000. 2006;40:77-93. 
Schroeder HE, Listgarten MA. The gingival tissues: the architecture of periodontal protection. Periodontol 2000. 1997;13:91-120.

Segal AW, Abo A. The biochemical basis of the NADPH oxidase of phagocytes. Trends Biochem Sci. 1993;18:43-7.

Sheppard FR, Kelher MR, Moore EE, McLaughlin NJ, Banerjee A, Silliman CC. Structural organization of the neutrophil NADPH oxidase: phosphorylation and translocation during priming and activation. J. Leukoc. Biol. 2005;78:1025-42.

Siemsen DW. Neutrophil Isolation from Nonhuman Species. In: Quinn, M., T. DeLeo, F., R. editors. Neutrophil Methods and Protocols. Humana Press. 2014. p. 19-37.

Simon SI, Cherapanov V, Nadra I, Waddell TK, Seo SM, Wang Q, Doerschuk CM, Downey GP. Signaling functions of L-selectin in neutrophils: alterations in the cytoskeleton and colocalization with CD18. J Immunol. 1999;163(5):2891-901.

Soehnlein O. Direct and alternative antimicrobial mechanisms of neutrophil-derived granule proteins. J Mol Med. 2009;87(12):1157-64.

Southwick FS, Stossel TP. Contractile proteins in leukocyte function. Semin Hematol. 1983;20:305-21.

Urban CF, Emert D, Schmid M, Abu-Abed U, Goosmann C, Nacken W, Brinkmann V, Jungblut PR, Zychlinsky A. Neutrophil extracellular traps contain calprotectin, a cytosolic protein complex involved in host defense against Candida albicans. PLoS Pathog. 2009;5(10):e1000639.

Wang Y, Li M, Stadler S, Correll S, Li P, Wang D, Hayama R, Leonelli L, Han H, Grigoryev SA, et al. Histone hypercitrullination mediates chroma- tin decondensation and neutrophil extracellular trap formation. J Cell Biol. 2009;184(2):205-13.

Wittmann S, Fröhlich D, Daniels S. Characterization of the human fMLP receptor in neutrophils and in Xenopus oocytes. British Journal of Pharmacology. 2002;135(6), 1375-82.

Yousefi S, Mihalache C, Kozlowski E, Schmid I, Simon HU. Viable neutrophils release mitochondrial DNA to form neutrophil extracellular traps. Cell Death Differ. 2009;16:1438-44. 
Zhang XQ, Kluger Y, Nakayama Y. Gene expression in mature neutrophils: early responses to inflammatory stimuli. J Leukoc Biol. 2004;75:358-72.

Zigmond SH. Chemotaxis by polymorphonuclear leukocytes. J Cell Biol. 1978;77:269_ 87 